\section{orin}

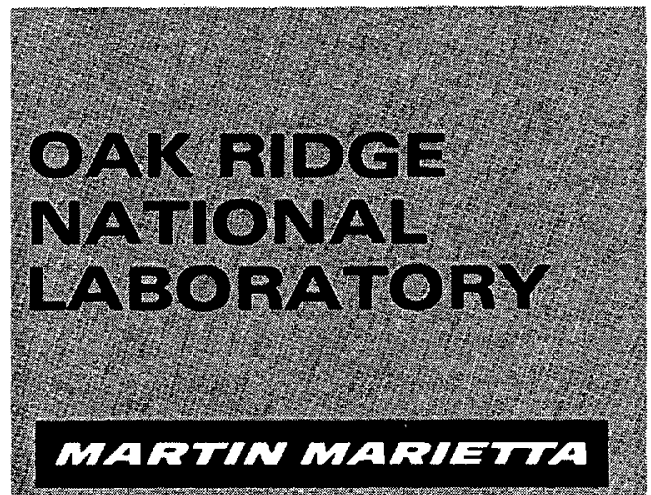

\section{Fuel Used for Off-Highway Recreation}

\author{
Patriola S. Hu \\ David Trumble \\ An Lu
}

ORNL-6794 
This report has been reproduced directly from the best available copy.

Available to DOE and DOE contractors from the Office of Scientific and Technical Information, P.O. Box 62, Oak Ridge, TN 37831; prices available from (615) 576-8401, FTS 626-8401.

Available to the public from the National Technical Information Service, U.S. Department of Commerce, 5285 Port Royal Rd., Springfield, VA 22161.

This report was prepared as an account of work sponsored by an agency of the United States Government. Neither the United States Government nor any agency thereof, nor any of their employees, makes any warranty, express or implied. or essumes any legal liability or responsibility for the accuracy, completeness, or usefulness of any information, apparatus, product, or process disclosed, or represents that its use would not infringe privately owned rights. Reference herein to any specific commercial product, process, or service by trade name, trademark, manufacturer, or otherwise, does not necessarily constitute or imply its endorsement, recommendation, or favoring by the United States Government or any agency thereof. The views and opinions of authors expressed herein do not necessarily state or reflect those of the United States Government or any agency thereof. 



\title{
FUEL USED FOR OFF-HIGHWAY RECREATION
}

\author{
Patricia S. Hu \\ David Trumble \\ An $\mathrm{Lu}$
}

Published July 1994

\author{
Prepared for the \\ Office of Highway Information Management \\ Federal Highway Administration \\ U.S. Department of Transportation \\ Washington, D.C. 20590 \\ Prepared by the \\ Statistics and Data Analysis Group \\ Center for Transportation Analysis \\ OAK RIDGE NATIONAL LABORATORY \\ managed by \\ MARTIN MARIETTA ENERGY SYSTEMS, INC. \\ for the \\ U.S. DEPARTMENT OF ENERGY \\ under \\ Contract No. DE-AC05-840R21400
}




\section{TABLE OF CONTENTS}

LIST OF TABLES $\ldots \ldots \ldots \ldots \ldots \ldots \ldots \ldots \ldots \ldots \ldots \ldots \ldots \ldots \ldots \ldots \ldots \ldots$

LIST OF FIGURES $\ldots \ldots \ldots \ldots \ldots \ldots \ldots \ldots \ldots \ldots \ldots \ldots \ldots \ldots$ vi

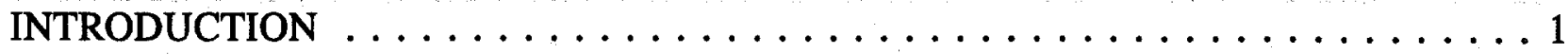

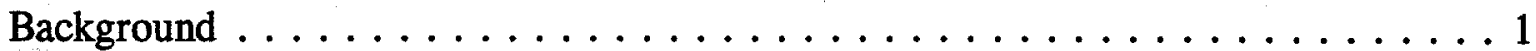

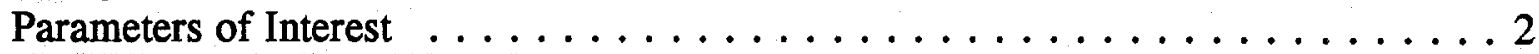

General Modeling Approach $\ldots \ldots \ldots \ldots \ldots \ldots \ldots \ldots \ldots$

PICKUP TRUCKS AND LIGHT UTILITY VEHICLES $\ldots \ldots \ldots \ldots \ldots \ldots \ldots \ldots \ldots$

Estimation Procedure . . . . . . . . . . . . . . . . . . 5

Comparison Between States' Estimates and ORNL's Estimates ........ 21

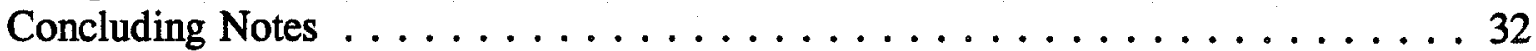

MOTORCYCLES AND ALL TERRAIN VEHICLES $\ldots \ldots \ldots \ldots \ldots \ldots \ldots \ldots$

Estimation Procedure . . . . . . . . . . . . . . . . . 33

Synthesis of Average Motorcycle and ATV Fuel Use Estimates . . . . . . . 39

SNOWMOBILES . . . . . . . . . . . . . . . . . . . . . 59

Estimation Procedure . . . . . . . . . . . . . . . . . . 59

Evaluation of States' Estimates of Snowmobile Usage . . . . . . . . . 67

CONCLUDING REMARKS $\ldots \ldots \ldots \ldots \ldots \ldots \ldots \ldots \ldots \ldots \ldots \ldots \ldots$

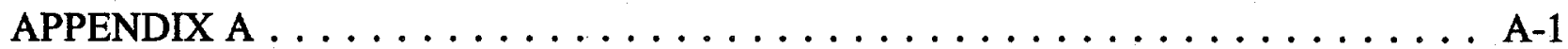




\section{LIST OF TABLES}

Table 1. Number of Off-Highway Motorized Recreational Vehicles and Their Corresponding Fuel Consumption for Year $t \ldots \ldots \ldots \ldots$

Table 2. Estimate of 1987 Light Truck Population, Average VMT per Truck, Percent Miles and Percent Trucks Used for Off-the-road Recreational Purposes . . . . . . 9

Table 3. Estimated Growth Rates of Trucks and Total Number of Light Trucks From 1987 to $1992 \ldots \ldots \ldots$. . . . . . . . . . . . . . . . . . . . . . . . . 13

Table 4. Estimated Number of Full Truck Equivalents Used Off-Road for Recreational Purposes, $1992 \ldots \ldots \ldots \ldots \ldots \ldots$. . . . . . . . . . . . . . . . . . . . . . . . .

Table 5. Estimated Growth Rates of Light Truck VMT and the Estimated Average VMT per Light Truck, 1987 - 1992 . . . . . . . . . . . . . . . . . . . 16

Table 6. Projected Average Annual VMT per Light Truck and Estimated Fuel Use Off-Road for Recreational Purposes by State, 1992 . . . . . . . . . . . . . 19

Table 7. Comparison of ORNL's and State Estimates of Number of Light Trucks and Fuel Used for Off-Road Recreational Purposes, 1990-1991 . . . . . . . . . . 22

Table 8. Results from the 1990 Arizona Off-Highway Vehicle Survey . . . . . . . . . . 25

Table 9. 1989 Off-Road Recreational Fuel Use of California Light Trucks . . . . . . . . 27

Table 10. Estimated Number of Off-Highway Vehicles and Fuel Use in Oregon . . . . . . 29

Table 11. Results from 1986 Washington Off-Road Vehicle (ORV) Study . . . . . . . . . 31

Table 12. MIC's Estimate of Annual Motorcycle Gasoline Consumption . . . . . . . . . 36

Table 13. Estimated Number of Motorcycles Used Off-Road for Recreational

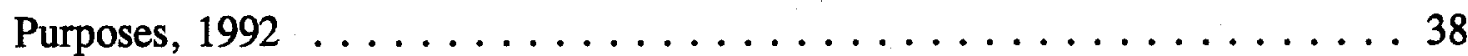

Table 14. Average Percent of ATVs Off-the-Road Riding for Recreational Purposes . . . 39

Table 15. Estimated Number of ATVs Used Off-Road for Recreational Purposes, 1992 . . 40

Table 16. Estimated Number of Arizona Motorcycles and ATVs Used Off-Highway . . . 44

Table 17. Estimated Number of California Motorcycles and ATVs Used Off-Road for Recreational Purposes and the Corresponding Fuel Use, 1989 . . . . . . . . . . 47

Table 18. Estimated Gasoline Consumption of Off-Road Vehicles in Colorado, 1991 . . . 48

Table 19. Comparison of Annual Fuel Use per Off-Highway Motorcycle and ATV . . . . 52

Table 20. Subjective Weights and Weighted Average Annual Fuel Consumption per Off-Highway Motorcycle and ATV $\ldots \ldots \ldots \ldots \ldots \ldots$ 


\section{LIST OF TABLES (continued)}

Table 21. Estimated Number of Motorcycles Used off the Road for Recreational Purposes and the Corresponding Fuel Consumption $-1992 \ldots \ldots \ldots \ldots 5$

Table 22. Estimated Number of ATVs Used off the Road for Recreational Purposes and the Corresponding Fuel Consumption $-1992 \ldots \ldots \ldots \ldots 7$

Table 23. Comparison Summary of States' Estimates of Total Number of Off-Highway Motorcycles and ATVs ................... 59

Table 24. Number of Registered Snowmobiles by States . . . . . . . . . . . . . 60

Table 25. Estimated Number of Snowmobiles Used for Off-Road Recreational Purposes and the Corresponding Fuel Consumption, $1992 \ldots \ldots \ldots 6$

Table 26. Average Annual Amount of Snow Fall and the Correction Factors For Snowmobile Usage . . . . . . . . . . . . . . . . . 66

Table 27. Estimated Number of Snowmobiles Used for Off-Highway in Arizona, $1990 \ldots \ldots \ldots \ldots$. . . . . . . . . . . . . . . . 68

Table 28. Estimates of California Snowmobile Off-Highway Recreational Fuel Use, 1989 . . . . . . . . . . . . . . . . . . . . . . . . . . . . . . . . 69

Table 29. Gas Consumption of Registered Snowmobiles Used in Minnesota

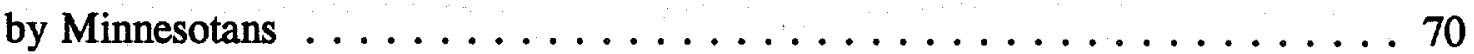

Table 30. Comparison of States' Snowmobile Fuel Use Estimates . . . . . . . . . . 73 Table 31. Estimated Fuel Used for Off-Highway Recreation by State, 1992 . . . . . . . . . 79 
- vi -

Fuel Used for Off-Highway Recreation

\section{LIST OF FIGURES}

Figure 1. Average Miles Ridden in the Past 12 Months Off-the-Road $\ldots \ldots \ldots$ 


\begin{abstract}
The Intermodal Surface Transportation Efficiency Act of 1991 (ISTEA) established a National Recreational Trails Funding Program and the National Recreational Trails Trust Fund. ISTEA requires that tax revenue generated from the sales of motor fuel used for off-highway recreation be transferred from the Highway Trust Fund to the Trails Trust Fund for recreational trail and facility improvements. In order to apportion the Trails Trust Fund to individual states equitably, the Federal Highway Administration (FHWA) asked the Oak Ridge National Laboratory (ORNL) to estimate the amount of motor fuel used for offhighway recreation at the state level by different vehicle types. This report documents this estimation procedure.
\end{abstract}

For this estimation procedure, off-highway recreational fuel use was defined as Federally taxed gasoline, gasohol, diesel fuel, or special fuel used in recreational motorized vehicles on recreational trails or back country terrain. Fuel used in outdoor non-engine recreational equipment, such as camp stoves, heaters, and lanterns, was excluded from our analysis. Vehicle types included in this study were: pickup truck, light utility vehicle, motorcycle, all terrain vehicle (ATV), and snowmobile.

Two factors governed the development of this estimation procedure. First, individual state shares of the total Trust Funds need to be developed using a uniform approach. Second, data needed for the estimation procedure should be publicly available and easily obtainable so that estimates for all subsequent years can be generated easily. Estimates were developed based on existing data sources. Adjustment factors were developed to take into account different vehicular offhighway recreational usage among states. 
Data are particularly sparse for motorcycles, ATVs and snowmobiles. Sparse data sources led to a number of assumptions in this estimation procedure. These assumptions typically reflect small state variations in vehicular off-highway recreational usage. In order to improve the estimates of vehicular off-highway recreational usage by state, future efforts need to acquire state-specific data. 


\section{INTRODUCTION}

\subsection{Background}

The Intermodal Surface Transportation Efficiency Act of 1991 (ISTEA) established a National Recreational Trails Funding Program and the National Recreational Trails Trust Fund. ISTEA requires that motor fuel tax revenues generated from the sales of motor fuel for off-highway recreational purposes be transferred from the Highway Trust Fund to the Trails Trust Fund for recreational trail and facility improvements. The motivation behind this Program was that while taxes were generated from sales of motor fuel used primarily for off-highway recreational purposes, no commensurate benefits were received by those who made those purchases. The amounts to be transferred to the Trails Trust Fund are determined by the U.S. Department of Treasury and are subject to the amounts authorized in ISTEA and annual appropriation by the U. S. Congress.

Under the ISTEA, the Federal Highway Administration (FHWA) is charged with the development of state by state estimates of the amount of fuel used for offhighway recreational purposes. These estimates will be used to apportion funds available in the National Recreational Trails Trust Fund to individual states. For generating these estimates, off-highway recreational fuel use has been defined as Federally taxed gasoline, gasohol, diesel fuel, or special fuel used in recreational motorized vehicles on recreational trails or back country terrain. Both registered and unregistered recreational motorized vehicles are included. Fuel used in outdoor non-engine recreational equipment, such as camp stoves, heaters, and lanterns has been excluded. The bulk of such equipment burns a nontaxable fuel known as white gasoline or by the trade name Coleman fuel or propane which is taxable only when used on highways. 
Charged with this mission, FHWA asked the Oak Ridge National Laboratory (ORNL) to develop a method to estimate the amount of motor fuel used for off-highway recreational purposes at the state level.

\subsection{Parameters of Interest}

Before an estimation procedure can be developed, it is essential to define clearly the parameters of interest. If a vehicle is used $35 \%$ of the time (i.e., $35 \%$ of the total annual miles) for off-highway recreational purposes, only a 0.35 fullvehicle-equivalent (FVE) is counted, and only fuel used for that $35 \%$ of the time is included in the tabulation. Two parameters of interest at the state level are:
$N_{i, j}=$ the number of the $i$ th type of motorized vehicles ("full vehicle equivalent") used for off-highway recreational purposes in state $j$, and

$$
\begin{aligned}
G a l_{i, j}= & \text { the total amount of fuel consumed by the } i \text { th type of "full } \\
& \text { vehicle equivalent" motorized vehicles for off-highway } \\
& \text { recreational purposes in state } j,
\end{aligned}
$$

where

$$
i= \begin{cases}1, & \text { for pickup trucks and light utility vehicles; } \\ 2, & \text { for motorcycles and all terrain vehicles (ATVs) } ; \text { and } \\ 3, & \text { for snowmobiles. }\end{cases}
$$

These parameters can be expressed in a tabular format, as in Table 1. For estimation purposes, the reference year $t$ is set at 1992. Historical time series data on $N_{i, j}$ and $\mathrm{Gal}_{i, j}$ are used to forecast statistics for years beyond 1992. 
Table 1. Number of Off-Highway Motorized Recreational Vehicles ${ }^{1}$ and Their Corresponding Fuel Consumption for Year $t$

\begin{tabular}{|c|c|c|c|c|c|c|}
\hline \multirow[t]{2}{*}{ State $^{2}$} & \multicolumn{2}{|c|}{$\begin{array}{l}\text { Pickup Trucks and } \\
\text { Utility Vehicles }\end{array}$} & \multicolumn{2}{|c|}{$\begin{array}{c}\text { Motorcycles and } \\
\text { ATVs }\end{array}$} & \multicolumn{2}{|c|}{ Snowmobiles } \\
\hline & Number & Fuel Use & Number & Fuel Use & Number & Fuel Use \\
\hline AL & $N_{1,1}$ & $\mathrm{Gal}_{1,1}$ & $N_{2,1}$ & $\mathrm{Gal}_{2,1}$ & $N_{3,1}$ & $\mathrm{Gal}_{3,1}$ \\
\hline AR & $N_{1,2}$ & $\mathrm{Gal}_{1,2}$ & $N_{2,2}$ & $\mathrm{Gall}_{2,2}$ & $N_{3,2}$ & $\mathrm{Gal}_{3,2}$ \\
\hline $\mathrm{AZ}$ & $N_{1,3}$ & $\mathrm{Gal}_{1,3}$ & $N_{2,3}$ & $\mathrm{Gal}_{2,3}$ & $N_{3,3}$ & $\mathrm{Gal}_{3,3}$ \\
\hline $\mathrm{CA}$ & $N_{1,4}$ & $\mathrm{Gal}_{1,4}$ & $N_{2,4}$ & $\mathrm{Gal}_{2,4}$ & $N_{3,4}$ & $\mathrm{Gal}_{3,4}$ \\
\hline . & . & . & . & . & - & - \\
\hline · & $\cdot$ & $\cdot$ & $\cdot$ & $\cdot$ & · & · \\
\hline WY & $N_{1,50}$ & $\mathrm{Gal}_{1,50}$ & $N_{2,50}$ & $\mathrm{Gal}_{2,50}$ & $N_{3,50}$ & $\mathrm{Gal}_{3,50}$ \\
\hline DC & $N_{1,51}$ & $\mathrm{Gal}_{1,51}$ & $N_{2,51}$ & $\mathrm{Gal}_{2,51}$ & $N_{3,51}$ & $\mathrm{Gal}_{3,51}$ \\
\hline
\end{tabular}

1 Full-vehicle-equivalent.

2 Includes the District of Columbia.

The rest of this technical memorandum is organized as follows. Section 2 documents the procedures developed to estimate the number of light trucks that are used for off-highway recreational purposes $\left(N_{l, j}\right)$, and the corresponding fuel use $\left(\mathrm{Gal}_{1, j}\right)$ for year $t$ and state $j$. Section 3 provides this information for motorcycles and ATVs; and Section 4 does the same for snowmobiles. Many states have submitted to FHWA their estimates of fuel used for off-highway recreational purposes (in responding to the National Recreational Trails Funding Program). This report compares the states' estimates and ORNL's estimates. Additionally, plausible explanations of the differences between these two sets of estimates are given for each vehicle category. A computer program is developed to generate vehicle stock estimates $\left(N_{i, j, i}\right)$ and fuel use estimates $\left(\operatorname{Gal}_{i, j,}\right)$. Appendix A includes the documentation for this program. 


\subsection{General Modeling Approach}

Estimates of the number of vehicles used for off-highway recreational purposes are mostly based on registration data, with a number of adjustment factors. The general relationship may be expressed as:

$$
\hat{N}_{i, j, t}=\operatorname{Reg}_{i, j, t} \times c_{1} \times c_{2} \times c_{3}
$$

$$
\begin{aligned}
& \text { where } \hat{N}_{i, j_{t} t}=\text { the estimated number of the } i \text { th type of } \\
& \text { motorized vehicles ("full vehicle equivalent") } \\
& \text { used for off-highway recreational purposes in } \\
& \text { state } j \text { year } t \text {, } \\
& \operatorname{Reg}_{i, j, t}=\text { the number of type } i \text { vehicles registered in state } j \text { and } \\
& \text { year } t \\
& c_{1}=\text { adjustment factor for unregistered vehicles; } \\
& c_{2}=\text { adjustment factor for vehicle being "used off- } \\
& \text { highway"; and } \\
& c_{3}=\text { adjustment factor for vehicle being "used for } \\
& \text { recreational purposes." }
\end{aligned}
$$

Fuel used for off-highway recreational purposes is calculated by multiplying the total number of vehicles $\hat{N}_{t, j, t}$ by the average annual fuel use for off-highway recreational purposes: 


$$
\operatorname{Gal}_{i, j, t}=\hat{N}_{t, j, t} \times G a l / \mathrm{Veh}_{t, j, t}
$$

where $G \hat{a} l_{t, j, t}=$ the estimated amount of fuel used by type $i$ vehicles in state $j$ during year $t$ for off-highway recreational purposes; and

$\mathrm{Gal} / \mathrm{Veh}_{i, j, t}=$ the average annual amount of fuel used per type $i$ vehicle in state $j$ during year $t$ for off-highway recreational purposes.

Several constraints played key roles in the development of this general modeling approach. First, the estimation procedures can only use data from existing sources, and preferably from sources with historical trends and with the likelihood of their continuing to be available. Second, the input data need to be publicly available and easily obtained. Therefore, this modeling approach does not make use of numerous locally available data.

\section{PICKUP TRUCKS AND LIGHT UTILITY VEHICLES}

\subsection{Estimation Procedure}

This section describes ORNL's computational procedures to estimate the total number of pickup trucks and light utility vehicles in each state which were used for off-highway recreational purposes and their corresponding fuel use. For the purpose of this study, "pickup trucks and light utility vehicles" (referred to as "light trucks" in the rest of this memorandum) include pickups, vans, minivans, and utility vehicles with a maximum gross vehicle weight less than or equal to 
10,000 pounds. Specifically, straight trucks with the body type of a pickup, van, minivan, or utility vehicle with the maximum gross weight less than or equal to 10,000 pounds were included in the analysis. Where data were missing on the maximum gross weight, the average weight was used. As mentioned earlier, the total number of vehicles used for recreational purposes is defined as the total number of "full vehicle equivalents". In other words, if 30 percent of a vehicle's total annual driving is off-the-road for recreational purposes, then this vehicle is counted as 0.30 of a full vehicle equivalent.

In order to estimate the number of light-duty trucks used off-the-road for recreational purposes and their corresponding fuel use, the following data are needed for each state: (1) total number of light-duty trucks registered in each state $\left(\operatorname{Reg}_{1, j, t}\right)$, (2) the average vehicle miles traveled (VMT) for off-highway recreational purposes per truck, and (3) the average off-road fuel economy (miles per gallon (MPG)). Because no data source includes all the information needed for this calculation, several data sources have been used to estimate each variable.

The most comprehensive data source identified on the number of light-duty trucks used for off-highway recreational purposes in each state is the Truck Inventory and Use Survey (TIUS). As a national transportation survey, TIUS collects data on the physical and operational characteristics of the nation's truck population. The survey is required by law to be conducted every 5 years for years ending in 2 and 7. TIUS has been conducted by the U.S. Bureau of Census.

There are four major factors that make the TIUS the foundation for estimating the number of light-duty trucks that are operated off-highway for recreational purposes. First, TIUS respondents were asked to report the average percentage of the miles that the vehicle was operated off-the-road. The adjustment 
factor $c_{2}$, as described in Equation 1, can be derived from these percentages. Second, these respondents were also asked to report the primary use (i.e., personal, business, or a combination of personal and business uses) for which their vehicles were typically operated during the TIUS years. Any vehicles primarily operated for business use are assumed to have no activities characterized as recreational. Third, information on truck weight, body type, and configuration was recorded so that light trucks which met the aforementioned criteria can be properly identified. Fourth, the TIUS excludes publicly-owned vehicles, ambulances, buses and motor homes from the survey. Consequently, no adjustment is necessary to eliminate activities of the publicly-owned vehicles from total aggregate estimates.

In the context of Equation (1), the adjustment factor $c_{1}$ for light truck estimates (adjusting for unregistered vehicles) is set at 1. This implies that all light trucks are assumed to be registered. Adjustment factor $c_{2}$, adjusting for off-theroad use, is simply the average percentage of the miles that a vehicle was used offthe-road as reported in TIUS. However, this input alone is not sufficient to estimate the percentage of the miles that a truck was operated off-highway for recreational purposes since it is possible that a truck was operated off-highway but not for recreational purposes. One example of this situation is vehicles used by the lumber industry, which are often operated off-the-road.

Since TIUS did not explicitly collect information on the percentage of the annual mileage that a vehicle was used off-the-road for recreational purposes, ORNL's estimation procedure assumed that the product of the percent miles used off-the-road and the percent miles used for personal use is a proxy of the probability that a truck will be used off-the-road for recreational purposes. This product provides the input for $c_{2} \times c_{3}$ of Equation (1). However, $c_{2} \times c_{3}$ was 
derived differently depending on the type of operation classification (i.e., personal, business, or a combination of both) under which the truck was primarily operated.

If the vehicle was primarily used for personal purposes, $c_{3}$ (the adjustment factor for recreational use) is assumed to be one. The rationale is that if a truck is primarily operated for personal use, then it is highly likely that the vehicle is used off-the-road exclusively for recreational purposes. Therefore, the adjustment factor for "use for recreational purposes", $c_{3}$, is 1 . On the other hand, if a truck is primarily operated for business, then the adjustment factor for "use for recreational purposes", $c_{3}$, is 0 . If a truck is operated for a mixture of personal and business purposes, then the probability that this truck will be operated off-the-road for recreational purposes is approximated by the product of the percent miles used off-the-road and the percent miles used for personal purposes.

\section{Base Year Calculation}

Since the 1987 TIUS is the most recent one with publicly available data, the estimation procedure set 1987 as the base year and used the 1987 TIUS data to estimate $N_{1, j, 87}$ and $\mathrm{Gal}_{1, j, 87}$

Table 2 presents the estimation results for each state for 1987 . The number of light trucks registered $\left(\operatorname{Reg}_{1, j, 87}\right)$ was estimated by summing the expansion factors of individual sampled pickup trucks and light utility vehicles (EXPFAC, the mnemonic data name in the TIUS public use file for the expansion factor). The percentage of light trucks used off-the-road for recreational purposes was 
Table 2. Estimate of 1987 Light Truck Population, Average VMT per Truck, Percent Miles and Percent Trucks Used for Off-the-road Recreational Purposes Based on the 1987 Truck Inventory and Use Survey

\begin{tabular}{|c|c|c|c|c|}
\hline & $\begin{array}{c}\text { Number of } \\
\text { Light Trucks } \\
\text { Registered }\end{array}$ & $\begin{array}{l}\text { Percent Trucks } \\
\text { Off-the-road }\end{array}$ & $\begin{array}{l}\text { Average VMT } \\
\text { Per Truck }\end{array}$ & $\begin{array}{l}\text { Percent Miles } \\
\text { Off-the-road }\end{array}$ \\
\hline $\begin{array}{l}\text { Alabama } \\
\text { Alaska } \\
\text { Arizona } \\
\text { Arkansas } \\
\text { California } \\
\text { Colorado } \\
\text { Connecticut } \\
\text { Delaware } \\
\text { D.C. } \\
\text { Florida } \\
\text { Georgia } \\
\text { Hawaii } \\
\text { Idaho } \\
\text { Ilinois } \\
\text { Indiana } \\
\text { Iowa } \\
\text { Kansas } \\
\text { Kentucky } \\
\text { Louisiana } \\
\text { Maine } \\
\text { Maryland } \\
\text { Massachusetts } \\
\text { Michigan } \\
\text { Minnesota } \\
\text { Mississippi } \\
\text { Missouri } \\
\text { Montana } \\
\text { Nebraska } \\
\text { Nevada } \\
\text { New Hampshire } \\
\text { New Jersey } \\
\text { New Mexico } \\
\text { New York } \\
\text { North Carolina } \\
\text { North Dakota } \\
\text { Ohio } \\
\text { Oklahoma } \\
\text { Oregon } \\
\text { Pennsylvania } \\
\text { Rhode Island } \\
\text { South Carolina } \\
\text { South Dakota } \\
\text { Tennessee } \\
\text { Texas } \\
\text { Utah } \\
\text { Vermont } \\
\text { Virginia } \\
\text { Washington } \\
\text { West Virginia } \\
\text { Wisconsin } \\
\text { Wyoming } \\
\text { Wyoung }\end{array}$ & $\begin{array}{r}779,605 \\
147,252 \\
673,819 \\
499,434 \\
4,073,798 \\
830,825 \\
368,130 \\
97,302 \\
16,932 \\
1,686,602 \\
1,043,230 \\
140,699 \\
271,568 \\
1,250,362 \\
905,827 \\
557,445 \\
583,485 \\
690,473 \\
812,373 \\
215,457 \\
551,808 \\
549,355 \\
1,301,830 \\
690,747 \\
460,260 \\
868,234 \\
258,134 \\
347,118 \\
219,378 \\
194,097 \\
631,449 \\
407,234 \\
1,268,290 \\
1,162,234 \\
184,650 \\
1,458,828 \\
759,614 \\
722,388 \\
1,389,534 \\
99,953 \\
510,957 \\
194,817 \\
889,064 \\
3,392,642 \\
322,628 \\
109,826 \\
977,791 \\
978,390 \\
368,984 \\
655,074 \\
187,252\end{array}$ & $\begin{array}{l}7.367 \\
3.892 \\
5.651 \\
6.101 \\
2.547 \\
5.077 \\
4.008 \\
2.933 \\
3.787 \\
3.069 \\
4.299 \\
6.041 \\
6.474 \\
3.298 \\
3.807 \\
2.609 \\
4.644 \\
4.699 \\
4.728 \\
5.246 \\
3.394 \\
2.447 \\
3.994 \\
3.249 \\
6.746 \\
3.653 \\
6.404 \\
4.468 \\
5.347 \\
4.426 \\
4.810 \\
7.615 \\
2.676 \\
3.427 \\
4.970 \\
2.326 \\
5.366 \\
3.849 \\
3.826 \\
4.567 \\
4.935 \\
5.398 \\
4.491 \\
4.174 \\
5.060 \\
4.952 \\
4.497 \\
4.305 \\
6.821 \\
3.734 \\
8.142\end{array}$ & $\begin{array}{r}10,458 \\
8,650 \\
11,437 \\
10,441 \\
10,859 \\
9,801 \\
10,796 \\
10,881 \\
9,558 \\
11,719 \\
11,467 \\
9,457 \\
9,481 \\
10,421 \\
10,370 \\
8,997 \\
9,392 \\
10,215 \\
11,438 \\
10,760 \\
11,890 \\
12,026 \\
11,872 \\
10,489 \\
10,518 \\
11,569 \\
8,249 \\
10,054 \\
9,894 \\
12,023 \\
11,575 \\
11,189 \\
10,601 \\
10,115 \\
8,458 \\
10,850 \\
11,094 \\
8,990 \\
10,191 \\
11,252 \\
11,771 \\
9,083 \\
10,971 \\
12,197 \\
10,019 \\
11,319 \\
10,351 \\
10,075 \\
\mathbf{8}, 780\end{array}$ & $\begin{array}{l}3.498 \\
3.193 \\
4.357 \\
5.765 \\
1.905 \\
4.228 \\
3.220 \\
1.752 \\
2.289 \\
3.090 \\
2.758 \\
4.879 \\
5.252 \\
2.254 \\
2.403 \\
1.984 \\
3.040 \\
3.233 \\
3.240 \\
3.912 \\
2.590 \\
1.636 \\
2.933 \\
2.235 \\
3.923 \\
3.180 \\
5.797 \\
2.575 \\
3.520 \\
3.151 \\
3.729 \\
7.331 \\
1.963 \\
2.420 \\
3.928 \\
1.751 \\
4.071 \\
2.583 \\
2.885 \\
3.356 \\
3.941 \\
3.635 \\
3.060 \\
3.003 \\
3.919 \\
3.108 \\
3.029 \\
2.274 \\
5.857 \\
2.643 \\
5.575\end{array}$ \\
\hline U.S.A. & $37,757,180$ & & 10,806 & \\
\hline
\end{tabular}

Source: Generated from the 1987 Truck Inventory and Use Survey (TIUS) Public Use Tape. 
estimated by the weighted average product of the percent miles that a truck was operated off-the-road (POFFRD) and the percent miles when it was used for personal purposes (PPTRAN). This percentage ranges from $2.3 \%$ for Ohio trucks to $8.1 \%$ for Wyoming trucks. The average annual miles traveled per truck was estimated by the weighted average of the miles driven in a year by individual trucks (ANNMIL). The percent of annual miles traveled off-the-road for recreational purposes was estimated by the weighted average product of the percentage of the miles that a truck was used off-the-road (POFFRD) and the percentage of the miles that it was used for personal purposes (PPTRAN), taking into account the annual miles driven by this truck (ANNMIL). All of the weighted averages are weighted by the sample expansion factors (EXPFAC).

Among 32,578 sampled trucks which qualified for this estimation procedure, ANNMIL data were missing for 3 trucks and POFFRD data were missing for 339 trucks. These missing values were imputed by specific body type and major operation classification (personal, business or mixed). The weighing procedure made sure that each truck carried its appropriate sampling weight, and all calculations were performed at the state level to maintain state specific estimates.

\section{Projections Beyond Base Year}

Projections of the vehicle stock

Since the 1987 TIUS is the most recent survey for which data are available, a projection procedure was developed to estimate statistics for years beyond 1987 . For years where auxiliary data are available, projections are accomplished by 
applying various growth rates calculated by the auxiliary data. However, for years where no auxiliary data are available, projections are accomplished by an exponential smoothing technique. For example, the vehicle stock of vehicle type $i$ in state $j$ and year $t+1$ is projected as:

$$
\operatorname{Reg}_{i, j, t+1}=f\left[t, j, \operatorname{Reg}_{i, j, t}, \ldots, \operatorname{Reg}_{i, 1, t-l}\right]
$$

where $f[$.] is a state-specific exponential smoothing model. This technique is recommended due to the relatively short time series available (usually ten years or less) and the ease of model maintenance.

To calculate the growth rates of the light truck vehicle stock, two data sources were evaluated: FHWA's Highway Statistics and the truck registration files compiled annually by R. L. Polk and Company. FHWA's data are based on registration data submitted by individual states. This data series reports privatelyowned vehicles combined with commercial vehicles. To exclude commercial vehicles from the reported aggregate totals, the commercial vehicle share of the combined private and commercial vehicle total needs to be estimated. Furthermore, it is unclear whether FHWA's data series includes minivans. Due to these unresolved data issues, this data series was not used at this time in the estimation and the projection procedures.

R. L. Polk and Company also obtains its registration data from individual states. Although this data series is far from perfect in terms of meeting this project's goals in that its vehicle stock numbers include all trucks, Polk's data series has two desirable features. First, it has been used as TIUS's sampling frame -- the basis from which trucks were identified and selected to participate in the surveys. Since the 1987 TIUS is the foundation for estimating $N_{1, j, 87}$ and $G a l_{1, j, 87}$, 
being TIUS' sampling frames provides a more compatible base for estimation purposes than other data sources. Second, it has been relatively consistent throughout the years in the types of vehicles included in its tabulations. Due to these two data features, the growth rates of light trucks were calculated based on Polk's data. These growth rates in conjunction with the 1987 base year estimates were used to estimate the total number of light trucks for years beyond 1987. The total number of light trucks for year $1987+l$ is estimated as:

$$
\operatorname{Reg}_{1, .(87+1)}=\operatorname{Reg}_{1, .(87+l-1)} \times \frac{\operatorname{Reg}_{1, .(87+))}(\text { Polk })}{\operatorname{Reg}_{1, .(87+l-1)}(\text { Polk })}
$$

where $l=1,2, \ldots$, and $\operatorname{Reg}_{1, ., 87}$, the number of light trucks for the year 1987, was based on the 1987 TIUS. Table 3 presents the calculation results. The distribution of vehicle stock by state was assumed to remain constant. The total number of light trucks in 1992 was "shared" to individual states by using the state distribution estimated by the 1987 TIUS data. The number of light trucks (in terms of fullvehicle-equivalents) that were used off-the-road for recreational purposes in 1992 is estimated by multiplying the number of light trucks in individual states by the state-specific probability that a light truck is used off-the-road for recreational purposes. These state-specific probabilities were calculated using 1987 TIUS data and were assumed to be constant over time (Table 2). Table 4 reports the estimated numbers of light trucks used off-the-road for recreational purposes in 1992 and the distribution of these vehicles by state. Note that the estimates of the number of light trucks used off-highway for recreational purposes are in fullvehicle-equivalents. 
Table 3. Estimated Growth Rates of Trucks and Total Number of Light Trucks From 1987 to 1992

\begin{tabular}{cccc}
\hline Model Year & $\begin{array}{c}\text { Total Trucks } \\
\text { in Operation }\end{array}$ & Growth rate & $\begin{array}{c}\text { Estimated Total } \\
\text { Number of } \\
\text { Light Trucks }\end{array}$ \\
\hline 1987 & $47,344,000$ & - & $37,757,180^{2}$ \\
1988 & $50,222,000$ & 1.061 & $40,052,406$ \\
1989 & $53,202,000$ & 1.059 & $42,428,977$ \\
1990 & $56,023,000$ & 1.053 & $44,678,745$ \\
1991 & $58,179,000$ & 1.038 & $46,398,170$ \\
1992 & $61,172,000$ & 1.051 & $48,785,109$ \\
\hline
\end{tabular}

1 R. L. Polk data as reported in a table entitled "Motor Trucks in Operation by Model Year" in MVMA's "Motor Vehicle Facts \& Figures '92".

2 Generated from the 1987 TIUS Public Use Tape.

Projections of fuel use

A very similar approach was used to project the amount of fuel consumed for off-the-road recreational purposes. Since only the average number of miles traveled off-the-road for recreational purposes is known (Table 2), this mileage information needs to be converted to the amount of fuel consumed. First, growth rates of annual miles of travel (VMT) for light trucks were calculated using the average annual VMT for 2-axle 4-tire trucks as published in Table VM-1 of FHWA's Highway Statistics. VMT for 2-axle 4-tire trucks was used to calculate VMT growth rates because 2-axle 4-tire trucks better represent light trucks than other truck categories used in Table VM-1 of the Highway Statistics. VMT growth rates are, in turn, used to "expand" the 1987 VMT calculated by using the 1987 TIUS data. The reason for not directly using VMT statistics from the 
Table 4. Estimated Number of Full Truck Equivalents Used Off-Road for Recreational Purposes, 1992

\begin{tabular}{|c|c|c|c|}
\hline State & $\begin{array}{c}\text { Projected Total Number of } \\
\text { Light Trucks }\end{array}$ & \multicolumn{2}{|c|}{$\begin{array}{l}\text { Full Truck Equivalents Used } \\
\text { Off-Road }\end{array}$} \\
\hline Alabama & $1,007,308$ & 74,208 & $(3.7 \%)$ \\
\hline Alaska & 190,261 & 7,405 & $(0.4 \%)$ \\
\hline Arizona & 870,625 & 49,199 & $(2.5 \%)$ \\
\hline Arkansas & 645,306 & 39,370 & $(2.0 \%)$ \\
\hline California & $5,263,653$ & 134,065 & $(6.8 \%)$ \\
\hline Colorado & $1,073,488$ & 54,501 & $(2.7 \%)$ \\
\hline Connecticut & 475,652 & 19,064 & $(1.0 \%)$ \\
\hline Delaware & 125,721 & 3,687 & $(0.2 \%)$ \\
\hline D. C. & 21,877 & 828 & $(0.0 \%)$ \\
\hline Florida & $2,179,216$ & 66,880 & $(3.4 \%)$ \\
\hline Georgia & $1,347,931$ & 57,948 & $(2.9 \%)$ \\
\hline Hawaii & 181,794 & 10,982 & $(0.6 \%)$ \\
\hline Idaho & 350,886 & 22,716 & $(1.1 \%)$ \\
\hline Illinois & $1,615,562$ & 53,281 & $(2.7 \%)$ \\
\hline Indiana & $1,170,396$ & 44,557 & $(2.2 \%)$ \\
\hline Iowa & 720,261 & 18,792 & $(0.9 \%)$ \\
\hline Kansas & 753,906 & 35,011 & $(1.8 \%)$ \\
\hline Kentucky & 892,143 & 41,922 & $(2.1 \%)$ \\
\hline Louisiana & $1,049,647$ & 49,627 & $(2.5 \%)$ \\
\hline Maine & 278,387 & 14,604 & $(0.7 \%)$ \\
\hline Maryland & 712,977 & 24,198 & $(1.2 \%)$ \\
\hline Massachusetts & 709,808 & 17,369 & $(0.9 \%)$ \\
\hline Michigan & $1,682,062$ & 67,182 & $(3.4 \%)$ \\
\hline Minnesota & 892,497 & 28,997 & $(1.5 \%)$ \\
\hline Mississippi & 594,690 & 40,118 & $(2.0 \%)$ \\
\hline Missouri & $1,121,823$ & 40,980 & $(2.1 \%)$ \\
\hline Montana & 333,528 & 21,359 & $(1.1 \%)$ \\
\hline Nebraska & 448,502 & 20,039 & $(1.0 \%)$ \\
\hline
\end{tabular}




\begin{tabular}{|c|c|c|c|}
\hline State & $\begin{array}{c}\text { Projected Total Number of } \\
\text { Light Trucks } \\
\end{array}$ & \multicolumn{2}{|c|}{$\begin{array}{c}\text { Full Truck Equivalents Used } \\
\text { Off-Road }\end{array}$} \\
\hline Nevada & 283,453 & 15,156 & $(0.8 \%)$ \\
\hline New Hampshire & 250,788 & 11,100 & $(0.6 \%)$ \\
\hline New Jersey & 815,879 & 39,244 & $(2.0 \%)$ \\
\hline New Mexico & 526,177 & 40,068 & $(2.0 \%)$ \\
\hline New York & $1,638,726$ & 43,852 & $(2.2 \%)$ \\
\hline North Carolina & $1,501,694$ & 51,463 & $(2.6 \%)$ \\
\hline North Dakota & 238,582 & 11,858 & $(0.6 \%)$ \\
\hline Ohio & $1,884,915$ & 43,843 & $(2.2 \%)$ \\
\hline Oklahoma & 981,478 & 52,666 & $(2.7 \%)$ \\
\hline Oregon & 933,379 & 35,926 & $(1.8 \%)$ \\
\hline Pennsylvania & $1,795,382$ & 68,691 & $(3.5 \%)$ \\
\hline Rhode Island & 129,147 & 5,898 & $(0.3 \%)$ \\
\hline South Carolina & 660,195 & 32,581 & $(1.6 \%)$ \\
\hline South Dakota & 251,718 & 13,588 & $(0.7 \%)$ \\
\hline Tennessee & $1,148,737$ & 51,590 & $(2.6 \%)$ \\
\hline Texas & $4,383,548$ & 182,969 & $(9.2 \%)$ \\
\hline Utah & 416,860 & 21,093 & $(1.1 \%)$ \\
\hline Vermont & 141,903 & 7,027 & $(0.4 \%)$ \\
\hline Virginia & $1,263,379$ & 56,814 & $(2.9 \%)$ \\
\hline Washington & $1,264,153$ & 54,422 & $(2.7 \%)$ \\
\hline West Virginia & 476,755 & 32,519 & $(1.6 \%)$ \\
\hline Wisconsin & 846,405 & 31,605 & $(1.6 \%)$ \\
\hline Wyoming & 241,944 & 19,699 & $(1.0 \%)$ \\
\hline TOTAL & $48,785,109$ & $1,982,564$ & $(100.0 \%)$ \\
\hline
\end{tabular}


Highway Statistics for years beyond 1987 was that VMT statistics from the Highway Statistics include all 2-axle 4-tire trucks, while the base year 1987 VMT was calculated using a specific group of sample trucks that met the vehicle definition requirements of this study. Table 5 reports the average annual VMT per 2-axle 4-tire truck, VMT growth rates, and the estimated average annual VMT per light truck that met the vehicle definitions of this study for years beyond 1987.

Table 5. Estimated Growth Rates of Light Truck VMT and the Estimated Average VMT per Light Truck,

1987 - 1992

\begin{tabular}{||cccc||}
\hline Year & $\begin{array}{c}\text { Average VMT } \\
\text { per Truck }^{1}\end{array}$ & Growth Rate & $\begin{array}{c}\text { Estimated } \\
\text { Average VMT per } \\
\text { Light Truck }\end{array}$ \\
\hline 1987 & 11,591 & - & $10,806^{2}$ \\
1988 & 11,848 & 1.022 & 11,046 \\
1989 & 11,982 & 1.011 & 11,171 \\
1990 & 11,993 & 1.001 & 11,181 \\
1991 & 12,103 & 1.009 & 11,283 \\
1992 & 12,055 & 0.996 & 11,239 \\
\hline
\end{tabular}

From Table VM-1 of the "Highway Statistics" under "2-Axle and 4-Tire" category. Based on the 1987 TIUS.

To maintain the different levels of vehicle usage by each state, the 1992 average annual VMT per light truck in state $j$ was calculated as: 


$$
V \hat{M} T_{1, j, 92}=\frac{V M T_{1, j, 87}}{V M T_{1, ., 87}} \times V \hat{M} T_{1, . .92}
$$

where $V \hat{V} T_{1, ., 92}=$ the 1992 national average miles traveled per light truck projected by using the 1987 TIUS data and VMT growth rates calculated from the FHWA's data (Table 5),

$$
V \hat{M T}_{1, ., 92}=11,239 \text {. }
$$

$V M T_{1, j, 87}=$ the 1987 average miles traveled per light truck in state $j$ (Table 2), and

$V M T_{1, ., 87}=$ the national average miles traveled per light truck in 1987 (Table 2).

Using Equation (5), the 1992 average VMT per light truck for state $j$ was estimated and presented in Table 6 . The total number of miles traveled for off-theroad recreational purposes by trucks in state $j$ was calculated by Equation (6).

$$
{ }_{o f f} V \hat{M} T_{1, j, 92}=\operatorname{Reg}_{1, j, 92} \times V \hat{M} T_{1, j, 92} \times\left(c_{2} \times c_{3}\right)_{j}
$$

where $\operatorname{Re}_{1,1,92}$ is the number of light trucks registered in state $j$ in 1992 (Table 4 ), and $\left(c_{2} \times c_{3}\right)_{j}$ is the state-specific probability that a truck in state $j$ is used for off-the-road recreational purposes (Table 2). 
The amount of fuel used off-the-road for recreational purposes is derived as:

$$
{ }_{\text {of }} \hat{G a l_{1, j, 92}}=\frac{\text { off } V \hat{M} T_{1, j, 92}}{M P G_{1, ., 92}}
$$

where of $M P G_{1, ., 92}$ is the estimated average 1992 off-the-road fuel economy of 2-axle 4-tire trucks and is estimated as:

$$
\text { off } M P G_{1, . .92}=\text { on } M P G_{1, ., 92} \times 0.9
$$

where on $M P G_{1, .,} 92$ is the average 1992 on-road fuel economy of 2-axle 4-tire trucks as reported in Table VM-1 of the Highway Statistics and 0.9 is the adjustment factor to take into account the difference between the on-road and the off-road fuel economies. This adjustment factor is based on data collected in the 1987 TIUS. Off-the-road fuel economy is assumed to be uniform among all states. The results are presented in Table 6. Also included in Table 6 is the average annual fuel used for off-the-road recreation per vehicle. Since the estimated number of vehicles used for off-the-road recreational purposes is expressed in fullvehicle-equivalents, one should not divide the amount of fuel used by the number of full-vehicle-equivalents used for off-the-road recreational purposes to derive the average amount of fuel use per truck for off-the-road recreation. Instead, this parameter should be calculated by dividing the amount of fuel used for off-the-road recreational purposes by the total number of light trucks. 
Table 6. Projected Average Annual VMT per Light Truck and Estimated Fuel Use Off-Road for Recreational Purposes by State, 1992

\begin{tabular}{|c|c|c|c|c|}
\hline State & $\begin{array}{c}\text { Projected Average } \\
\text { VMT per Light Truck }\end{array}$ & \multicolumn{2}{|c|}{$\begin{array}{c}\text { Total Fuel } \\
\text { Used Off-Road } \\
\text { (gal.) }\end{array}$} & $\begin{array}{c}\text { Average Fuel } \\
\text { Use Off-Road } \\
\text { per Light } \\
\text { Truck(gal.) }\end{array}$ \\
\hline Wabrina: & (16/67\% & $6 \% 61 \%$. & 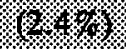 & 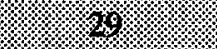 \\
\hline 4 & $6.9 \%$ & $8422 \div 68$. & \% & 2 \\
\hline 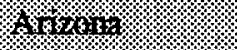 & (1\% & (3).6.6. & \% & 46. \\
\hline wh & 1) & 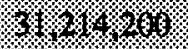 & (2. & 8.8. \\
\hline 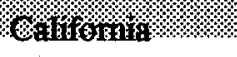 & $1 / 1,294$ & 8. & $(2 \times 6 \%$ & * \\
\hline Colorado & 10,194 & $35,747,660$ & $(2.9 \%)$ & 33 \\
\hline Connecticut & 11,228 & $13,287,790$ & $(1.1 \%)$ & 28 \\
\hline Delaware & 11,317 & $1,926,005$ & $(0.2 \%)$ & 15 \\
\hline D. C. & 9,941 & 384,639 & $(0.0 \%)$ & 18 \\
\hline Florida & $12 x 188$ & $63,415,330$ & $(5.1 \%)$ & 29 \\
\hline 6reops: & 4 & 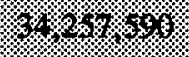 & (2) & 校: \\
\hline 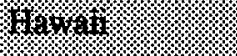 & (6) & $6 \%$ & 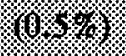 & $\%$ \\
\hline 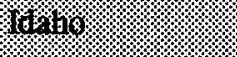 & (6) & 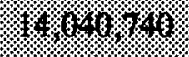 & (6) & $\sqrt[9]{9}$ \\
\hline 117in & (6) & (6) & $(x)$ & \% \\
\hline 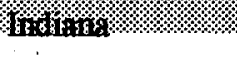 & (1) & $288,43 \% 460$ & $(x .9 .6 \%$ & 20 \\
\hline Iowa & 9,357 & $10,331,750$ & $(0.8 \%)$ & 14 \\
\hline Kansas & 9,768 & $17,297,930$ & $(1.4 \%)$ & 23 \\
\hline Kentucky & 10,624 & $23,676,820$ & $(1.9 \%)$ & 27 \\
\hline Louisiana & 11,896 & $31,259,590$ & $(2.5 \%)$ & 30 \\
\hline Maine: & 11.191 & 9416821 & $(0.8 \%)$ & 34 \\
\hline 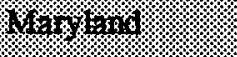 & 4.66 & 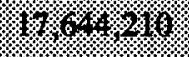 & (1/ & 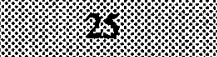 \\
\hline 14. & (3) & w. & 6 & \% \\
\hline Hixing.n. & y. & 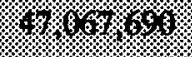 & (6x) & 2. \\
\hline 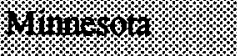 & 40 & 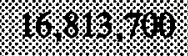 & 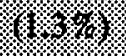 & 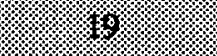 \\
\hline Mussisspppir & (6) & 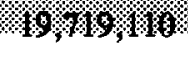 & $(126 \%$ & 3. \\
\hline Missouri & 12,032 & $33,165,950$ & $(2.6 \%)$ & 30 \\
\hline Montana & 10,457 & $12,816,880$ & $(1.0 \%)$ & 38 \\
\hline Nebraska & 8,579 & $9,330,951$ & $(0.7 \%)$ & 21 \\
\hline Nevada & 10,290 & $7,933,052$ & $(0.6 \%)$ & 28 \\
\hline New Hampshire & 12505 & 7.635 .064 & $(0.6 \%)$ & 30 \\
\hline 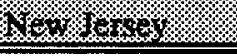 & 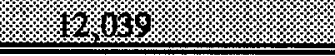 & 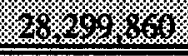 & (2) & 1. \\
\hline
\end{tabular}




\begin{tabular}{|c|c|c|c|c|}
\hline State & $\begin{array}{c}\text { Projected Average } \\
\text { VMT per Light Truck }\end{array}$ & \multicolumn{2}{|c|}{$\begin{array}{c}\text { Total Fuel } \\
\text { Used Off-Road } \\
\text { (gal.) }\end{array}$} & $\begin{array}{c}\text { Average Fuel } \\
\text { Use Off-Road } \\
\text { per Light } \\
\text { Truck(gal.) }\end{array}$ \\
\hline 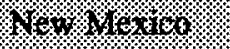 & \% $63 \%$ & $8468 \% 1606$ & $(28 \%)$ & 66 \\
\hline 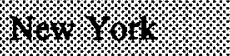 & 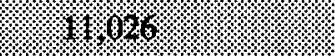 & 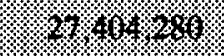 & $\%$ & \% \\
\hline 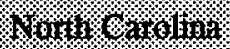 & (1) & $28,30 \% 8$ ing. & $(8.4 \%)$ & 26 \\
\hline 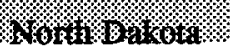 & 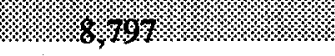 & $16,3699,3 \%$ & $(2.3 .5)$ & $22 ?$ \\
\hline Ohio & 11,285 & $28,777,470$ & $(2.3 \%)$ & 15 \\
\hline Oklahoma & 11,538 & $35,621,720$ & $(2.8 \%)$ & 36 \\
\hline Oregon & 9,350 & $17,417,560$ & $(1.4 \%)$ & 19 \\
\hline Pennsylvania & 10,599 & $42,419,390$ & $(3.4 \%)$ & 24 \\
\hline Rhode Island & 11.703 & $3,919,044$ & $(0.3 \%)$ & 30 . \\
\hline (4) & $12 \% 2 \%$ & $24.61 \% 486$ & $(261 \%$ & 3 \\
\hline 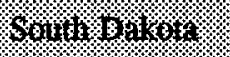 & (6) & $6.6 \% \%$ & (6) & \%?: \\
\hline 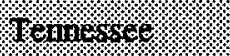 & 4 & 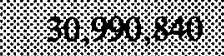 & $\%$ & 2: \\
\hline 8\% & 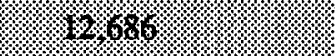 & $1264026 \% 590$ & $(10.3 \% \%$ & 29 \\
\hline Thatin: & 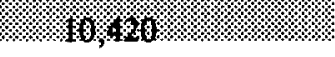 & (x) & $(1) 0 \% \%):$ & 3.2. \\
\hline Vermont & 11,772 & $4,011,685$ & $(0.3 \%)$ & 28 \\
\hline Virginia & 10,766 & $31,831,730$ & $(2.5 \%)$ & 25 \\
\hline Washington & 10,479 & $23,274,490$ & $(1.9 \%)$ & 18 \\
\hline West Virginia & 9,962 & $21,492,660$ & $(1.7 \%)$ & 45 \\
\hline Wisconsin & 10,764 & $18,604,520$ & $(1.5 \%)$ & 22 \\
\hline Wyoming & 9,132 & $9,516,966$ & $(0.8 \%)$ & 39 \\
\hline TOTAL & & $1,254,126,323$ & $(100.0 \%)$ & \\
\hline
\end{tabular}




\subsection{Comparison Between States' Estimates and ORNL's Estimates}

Twenty-one of the 51 states (including the District of Columbia) reported their estimates of light trucks used for off-the-road recreational purposes to FHWA in January 1992. Several states conducted off-highway vehicle surveys to estimate the numbers of off-highway light trucks used for recreational purposes and the corresponding fuel use. These surveys are discussed in detail later in this section. Since most of the estimates were based on 1991 data, the comparison between states' estimates and ORNL estimates was for the year 1991 (Table 7). In general, ORNL's statewide estimates of the number of light trucks are relatively close to the states' estimates. As mentioned earlier, light trucks in this study are defined by ORNL as straight trucks with body types of a pickup, van, minivan, or utility vehicle and maximum gross weight less than or equal to $10,000 \mathrm{lbs}$.

Differences in vehicle classification by ORNL and by the states contribute to the discrepancy, if any, between the two sets of vehicle stock estimates. While ORNL's estimation procedure includes minivans and vans, most of the states did not include vans and minivans, and some did not include utility vehicles. The reason that Georgia, Louisiana, and Wyoming reported a greater number of light trucks than ORNL did was probably because they included all of the registered light trucks in their calculations.

The majority of ORNL's state estimates of fuel used for off-the-road recreational purposes are higher than individual states' estimates, except for the 
Table 7. Comparison of ORNL's and State Estimates of Number of Light Trucks and Fuel Used for Off-Road Recreational Purposes, 1990-1991

\begin{tabular}{|c|c|c|c|c|c|c|}
\hline & \multicolumn{2}{|c|}{$\begin{array}{c}\text { Total Number of Light } \\
\text { Trucks (1000) }\end{array}$} & \multicolumn{2}{|c|}{$\begin{array}{c}\text { Total Fuel Used Off-Road } \\
\text { (1000 Gal.) }\end{array}$} & \multicolumn{2}{|c|}{$\begin{array}{c}\text { Average Fuel Use } \\
\text { Off-Road per Vehicle } \\
\text { (Gal.) }\end{array}$} \\
\hline & $\begin{array}{c}\text { ORNL } \\
\text { Estimate }\end{array}$ & $\begin{array}{c}\text { State } \\
\text { Estimate }\end{array}$ & $\begin{array}{c}\text { ORNL } \\
\text { Estimate }\end{array}$ & $\begin{array}{c}\text { State } \\
\text { Estimate }\end{array}$ & $\begin{array}{c}\text { ORNL } \\
\text { Estimate }\end{array}$ & $\begin{array}{c}\text { State } \\
\text { Estimate }\end{array}$ \\
\hline Alabama $^{1}$ & 779.6 & 820.6 & 24,603 & 65,299 & 32 & 80 \\
\hline Alaska & 181.0 & 135.5 & 3,988 & 356 & 22 & 3 \\
\hline Arizona ${ }^{2}$ & 797.3 & 759.0 & 32,281 & $N / A^{3}$ & 40 & N/A \\
\hline Arkansas ${ }^{1}$ & 499.4 & 512.1 & 25,933 & 52,862 & 52 & 103 \\
\hline California $^{4}$ & $4,577.9$ & $4,528.1$ & 78,997 & 31,064 & 17 & 7 \\
\hline Colorado & $1,021.0$ & $362.7^{5}$ & 33,758 & 1,451 & 33 & N/A \\
\hline Delaware & 119.6 & $5.7^{6}$ & 1,819 & 1,024 & 15 & N/A \\
\hline Georgia & $1,282.0$ & $1,399.1$ & 32,351 & 6,296 & 25 & 5 \\
\hline Idaho $^{2}$ & 321.4 & 306.7 & 13,001 & 10,126 & 40 & 48 \\
\hline Louisiana & 998.3 & $1,245.1$ & 29,520 & 10,954 & 30 & 9 \\
\hline Minnesota $^{2}$ & 817.4 & 528.3 & 15,569 & 4,552 & 19 & 9 \\
\hline Mississippi & 565.6 & 466.7 & 18,622 & 4,725 & 33 & 10 \\
\hline Nebraska & 426.6 & $171.6^{7}$ & 8,812 & 4,719 & 21 & N/A \\
\hline New Mexico & 500.4 & 456.8 & 32,754 & 1,978 & 65 & 4 \\
\hline New York & $1,558.5$ & $39.6^{7}$ & 25,879 & 3,477 & 17 & N/A \\
\hline North Dakota & 226.9 & 212.1 & 6,015 & 937 & 27 & 4 \\
\hline Oklahoma & 933.5 & $184.3^{7}$ & 33,639 & 9,217 & 36 & N/A \\
\hline Oregon & 887.7 & $3.8^{8}$ & 16,448 & 8,476 & 19 & 223 \\
\hline Pennsylvania & $1,707.5$ & $1,277.5$ & 40,059 & 192 & 23 & 0.2 \\
\hline Rhode Island & 122.8 & $99.5^{9}$ & 3,701 & 362 & 30 & 4 \\
\hline South Dakota ${ }^{2}$ & 230.5 & 193.7 & 6,184 & 2,124 & 27 & 11 \\
\hline Washington & $1,202.3$ & $270.9^{10}$ & 21,979 & 29,947 & 18 & N/A \\
\hline Wyoming & 230.1 & 215.2 & 8,987 & 3,076 & 39 & 14 \\
\hline Total & & & 482,618 & 253,214 & & \\
\hline
\end{tabular}

1987 data.

21990 data.

3 Data are not available.

41989 data as reported in Tyler and Associates,_A_Study to Determine Fuel Tax_Attributable to Off-Highway and Street_Licensed Vehicles Used for Recreation_aff-Highway.

5 Registered 4-wheel drive pickups only.

6 Registered surf fishing vehicles only.

7 Off-road recreational vehicle only.

8 Vehicles registered as of June 30, 1991 include dune buggies, jeeps, and other 4x4's, motor vehicles that weigh more than 600 but less than 8,000 pounds.

9 Light trucks from 4,000 - 10,000 pounds only.

10 Off-road pickups only. 
states of Alabama, Arkansas, and Washington. Two plausible explanations for Alabama's estimate of fuel used for off-the-road recreational purposes being almost two and half times higher than ORNL's estimate are: (1) the Alabama Highway Department assumed that $6.6 \%$ of the annual driving was for off-the-road recreational purposes while ORNL's estimate was 3.5\% (Table 2) which was derived using the 1987 TIUS data; and (2) Alabama's mileage estimates are converted to fuel consumption by setting the average fuel economy at 10 , while ORNL used adjusted FHWA's national estimate of 14.3 miles per gallon for 2-axle 4-tire trucks. The difference in the fuel economy estimate itself introduces a $30 \%$ difference in the fuel consumption estimate.

In the case of Arkansas, all recreational travel was assumed to be off-theroad recreational travel. It amounted to $13.3 \%$ of total travel. Based on the 1987 TIUS data, the percent miles traveled by light trucks for off-the-road recreational purposes in Arkansas was 5.8\% (Table 2). This difference alone contributes to Arkansas' estimate being double that of ORNL's.

In its effort to determine the proportion of motor vehicle fuel sold to snowmobiles and other off-road vehicles, the state of Washington conducted two studies: the 1986 Washington State Off-Road Vehicle Study, and the 1990-1991 Snowmobile Fuel Use Study. Given Washington's estimate of 270,900 off-road pickups and TIUS' estimate of 1,202,300 light trucks in Washington, $22.5 \%$ of all light trucks in Washington were assumed to be off-the-road pickups $(270,900 \div$ $1,202,300=22.5 \%)$. Applying Washington's estimate that $44 \%$ of its off-road pickup trucks $(4 \times 4 s)$ were used for recreational purposes, the percentage of the total light trucks used off-highway for recreational purposes in Washington is estimated to be $9.9 \%(22.5 \% \times 44.0 \%)$. This percentage is conservative since it assumes that only off-road vehicles are operated off-the-road. Nonetheless, this 
percentage estimate is more than double the ORNL estimate of $4.3 \%$ (Table 2). This difference probably contributes significantly to the difference in estimated fuel use for off-the-road recreational purposes.

The following discussion focuses on off-road vehicle surveys conducted by individual states.

\section{Arizona}

Two different surveys were conducted during 1989-1990 -- one for the winter and one for the summer season. Each survey covered a six month period and contacted 1,000 households using a random dialing procedure that selected a number of telephone numbers in proportion to each county's population size. These initial contacts estimated that $\mathbf{1 7 . 5}$ percent of the households in the winter sample and 19.3 percent of the households in the summer sample drove their offroad vehicles off-highway at least once during the six months prior to the survey. A low response rate in the initial contacts led to additional phone calls. Overall, 331 households indicated that they had driven their off-road vehicles off-highway during the six-month sample period in the Winter of 1989, and 353 households indicated that they had driven their off-road vehicles off-highway during the sixmonth sample period in the Summer of 1990. Unfortunately, the reported survey results do not include any usage information by vehicle class. Table 8 summarizes the population estimates. 
Table 8. Results from the 1990 Arizona Off-Highway Vehicle Survey $4 \times 4$ Pickups \& Vans/Trucks

\begin{tabular}{|c|c|c|}
\hline & $\begin{array}{c}\text { Estimated Total Truck } \\
\text { Population } \\
\end{array}$ & $\begin{array}{c}\text { Estimated Off-road Truck } \\
\text { Population } \\
\end{array}$ \\
\hline Based on the Winter Survey & 798,906 & 103,579 \\
\hline Based on the Summer Survey & 719,015 & 219,642 \\
\hline Survey Average & 758,961 & 161,611 \\
\hline ORNL Estimates & 797,348 & $215,503^{1}$ \\
\hline $\begin{array}{l}\text { \% Difference between ORNL's and Arizona's } \\
\text { Estimates }\end{array}$ & $5 \%$ & $33 \%$ \\
\hline
\end{tabular}

1 Used off-the-road for recreation purposes at some time.

Source: Virden, R. J., et. al., "The 1990 Arizona Off-Highway Vehicle Survey," Prepared for the Arizona Departments of Transportation and Game and Fish, and Arizona State Parks Board. Arizona State University, Tempe, Arizona, January 1991.

\section{California}

A randomly selected sample of 20,394 households were contacted. Of those, 12,156 surveys were completed, yielding a response rate of almost $60 \%$. The sample covered 53 of California's 58 counties. The sample was selected in proportion to each county's population size. The 5 counties which were not covered in the survey each represents no more than one-tenth of one percent of the state's total population. All panelists were interviewed four times, once every three months. Each respondent was sent a reminder postcard that notified him/her when he/she would be contacted (or re-contacted). Each respondent was also provided a diary to keep track of his/her off-road fuel use. Whether the sampled off-highway vehicles were registered was determined by matching the sampled vehicles with California's Department of Motor Vehicles' registration file of offhighway vehicles. Based on the matching results, a correction factor was 
computed to estimate the total number of off-road vehicles of a particular class. This factor was the ratio of unregistered vehicles to registered vehicles.

Light trucks were categorized in two groups: 4-wheel drive and 2-wheel drive. These vehicles include pickups, vans, and utility vehicles (including dune buggies). Survey results indicate that $36.1 \%$ of all street licensed 4 -wheel drive trucks were used off-the-road at some time during the 12-month period prior to the survey, and $13.9 \%$ of the street licensed 2 -wheel drives were similarly used. Survey results also suggested that out of 95 sampled non-street vehicles, only 11 could be matched with California DMV's registration files, indicating that $88 \%$ of non-street vehicles were unregistered. This implies an adjustment factor of 7.6 for unregistered light trucks. Any problem with the matching procedure could easily result in an over- or (under) estimate of the ratio of unregistered vehicles to registered vehicles. Table 9 presents the resulting population estimate of off-road light trucks.

A direct comparison between ORNL's and California's estimates is not straightforward. The types of vehicles included in the estimation procedure are different. ORNL's estimation procedure includes all registered pickups, vans, utility vehicles and minivans while California includes all pickups, vans and utility vehicles, but not minivans, regardless of whether the vehicles are registered or not. On average, ORNL estimated that each light truck used 17 gallons a year for offroad recreational purposes while California derived separate fuel use estimates for different vehicle classes (Table 9). Table 7 presents a comparison between these two sets of light truck estimates. 


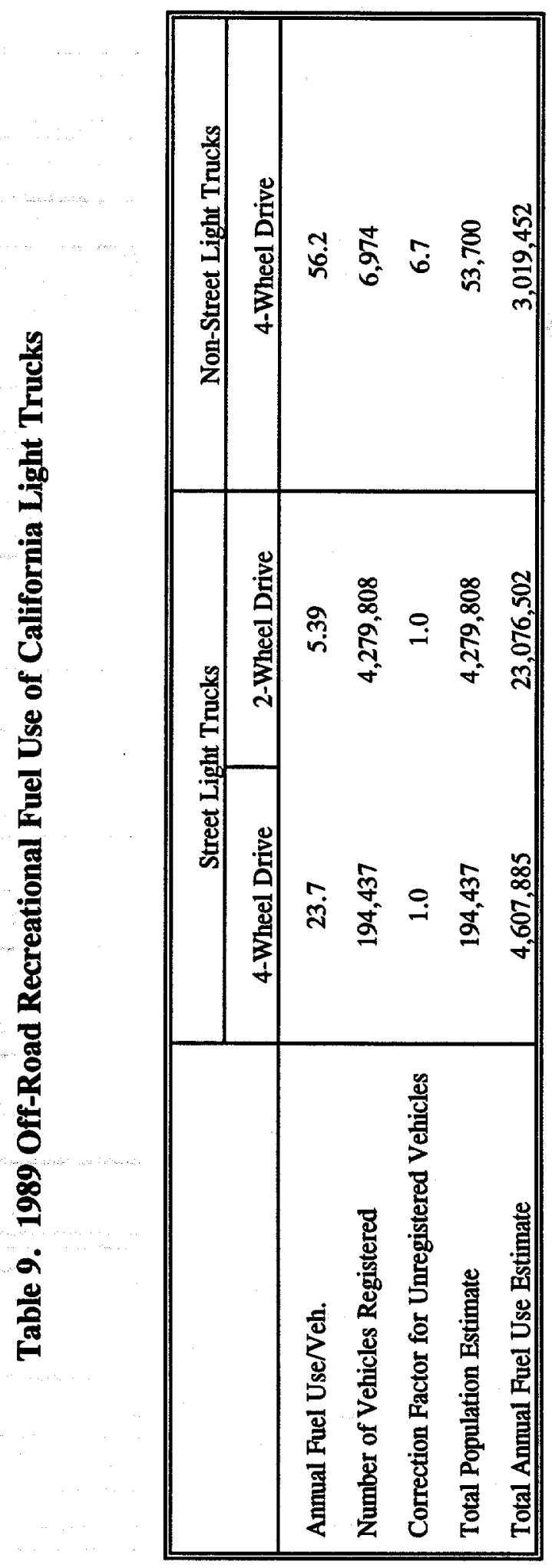




\section{Colorado}

A mail survey was done of randomly-selected registered off-road vehicles. Unfortunately, there is little documentation of the survey results. Since no information is available regarding the important factors, such as the number of households surveyed or the response rate, etc., no assessment is made of the survey results. The State of Colorado estimated that eight percent of its total 362,700 4wheel drive vehicles traveled off-the-road, resulting in an estimate of 29,016 offhighway 4-wheel drive vehicles. Each of these off-highway vehicles was assumed to use 50 gallons of fuel per year, yielding a total fuel use estimate of $1,450,800$ gallons. The lack of documentation makes it impossible to evaluate the differences between ORNL's estimates and the State of Colorado's estimates.

\section{Oregon}

An off-road vehicle use survey was conducted on randomly-selected registered off-road vehicles. This survey was updated every four years as required by law. No effort was made to survey non-registered vehicles. A summary of the survey results is presented in Table 10 . The survey response rate was about $70 \%$ which is reasonably good for a voluntary survey. These annual fuel consumption estimates illustrate the difference between consumption estimates reported directly by survey respondents and estimates computed by the average number of days operated off-road for recreational purposes (Days) and the average fuel use per day for off-the-road recreation purposes (Gallons). The fact that the average of the product of Days and Gallons [Mean(Days $\times$ Gallons)] is greater than the product of the averages [Mean(Days) $x$ Mean(Gallons)] indicates that Days and Gallons are positively correlated. Furthermore, there is no supporting evidence to believe that Mean(Days $\times$ Gallons) is a better estimate than the annual fuel use reported 
Table 10. Estimated Number of Off-Highway Vehicles and Fuel Use in Oregon (Based on Results from the 1989 Oregon Off-Road Vehicles Survey)

\begin{tabular}{|c|c|c|c|}
\hline & $\begin{array}{l}\text { Off-Highway } \\
\text { Motorcycles }\end{array}$ & ATV's & $\begin{array}{l}\text { Jeeps } \\
\& 4 \times 4 s\end{array}$ \\
\hline Licensed vehicles & 1,489 & 41,211 & 3,016 \\
\hline No. of vehicles surveyed & 494 & 711 & 592 \\
\hline Competed surveys & 374 & 513 & 402 \\
\hline No. of surveys without missing data & 346 & 488 & 371 \\
\hline No. of vehicles used for recreation only & 331 & 390 & 307 \\
\hline \multicolumn{4}{|c|}{ 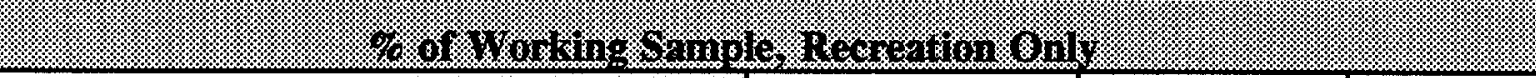 } \\
\hline Not used for recreational purposes & 0.05 & 0.25 & 0.21 \\
\hline Owning the vehicle less than a year & 0.50 & 0.17 & 0.18 \\
\hline \multicolumn{4}{|c|}{ 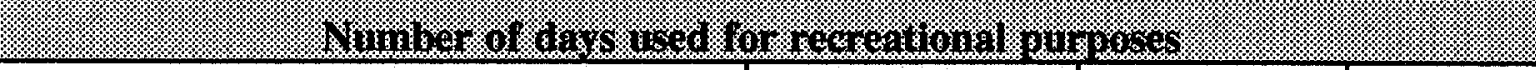 } \\
\hline Average & 33.0 & 34.9 & 30.6 \\
\hline \multicolumn{4}{|c|}{ 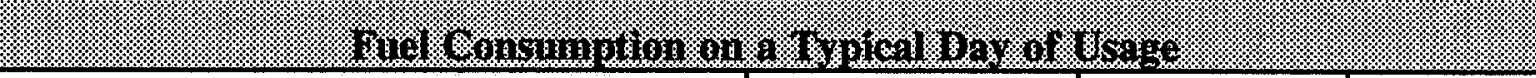 } \\
\hline Average & 2.4 & 2.9 & 6.4 \\
\hline Median & 2.0 & 2.0 & 5.0 \\
\hline \multicolumn{4}{|c|}{ 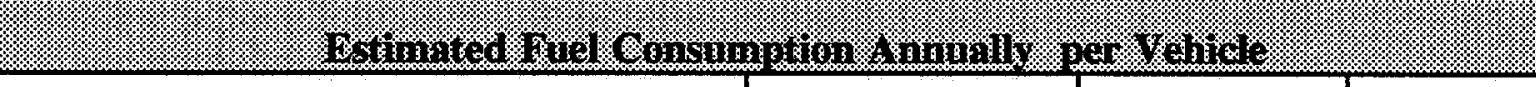 } \\
\hline Avg (Days x Gallons) & 89.3 & 125.6 & 223.2 \\
\hline Avg (Days) x Avg (Gallons) & 79.2 & 101.2 & 195.8 \\
\hline Reported in the survey & 59.3 & 81.6 & 166.2 \\
\hline \multicolumn{4}{|c|}{ 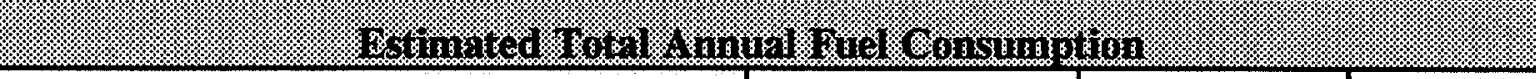 } \\
\hline Reported in the survey & 132,968 & $5,176,102$ & 673,171 \\
\hline Corrected for recreational use & 126,942 & $3,875,440$ & 532,836 \\
\hline
\end{tabular}


directly by the survey respondents. Based on the survey results, an adjustment factor of $79 \%$ was derived to account for the fuel used off-road for recreational purposes.

A significant definitional difference between ORNL's procedure and the State of Oregon's procedure is that Oregon's 1989-1990 ATV Survey focused on ATV Class II vehicles which included only three classes of all terrain vehicles: dune buddies, jeeps, and other 4X4's motor vehicles that weigh more than 600 but less than 8,000 pounds. In March 1990, there were 3,016 Class II ATV licenses maintained by the Motor Vehicle Division of the Oregon Department of Transportation. This number of Class II ATV licenses indicates that Oregon's estimates are based on information collected from a sample of light trucks which are classified as ATVs, rather than a sample of light trucks that were used off-theroad for recreational purposes. Consequently, Oregon's estimates are significantly lower than ORNL's estimates (Table 7).

\section{Washington}

A telephone survey of 3,460 households was conducted in 1986 regarding off-road recreational vehicle usage in 1985 . The method that was used to select telephone numbers is not documented. The sample size within each district in the State was proportional to the population of the counties making up the district. The survey identified 763 households owning one or more off-road vehicles (ORV). The parameters at the state level were then estimated by proportionally weighing the survey results by the sampling expansion factors. These estimates together with other relevant statistics are reported in Table 11. Also reported in Table 11 is a confidence range with an unspecified level of significance. A comparison with ORNL's estimates of the number of off-road light trucks in 1987 
yields a difference of $43,919(=262,341-218,422)$ which is almost twice the reported confidence range $(23,522)$.

A follow up mail survey was also conducted with the owners identified in the telephone survey. About $41 \%$ of these households returned a completed survey. The limited response rate decreases the reliability of the survey's results. Also, the survey did not include any questions regarding fuel consumption, information needed for our study.

Table 11. Results from 1986 Washington Off-Road Vehicle (ORV) Study Sample size $=3,460$ Households

\begin{tabular}{||l|c|c|c|c||}
\hline \hline & $\begin{array}{c}\text { No. Households } \\
\text { in Survey Owning } \\
\text { ORVs }\end{array}$ & $\begin{array}{c}\text { \% Households } \\
\text { in Survey } \\
\text { Owning ORVs }\end{array}$ & $\begin{array}{c}\text { 1985 Projected } \\
\text { State-Wide } \\
\text { Totals }\end{array}$ & $\begin{array}{c}\text { Confidence } \\
\text { Range }\end{array}$ \\
\hline $4 \times 4 s$ & 450 & $13 \%$ & 218,422 & 23,522 \\
Dune buggies & 35 & $1 \%$ & 9,314 & 6,721 \\
Dirt bikes & 415 & $12 \%$ & 195,740 & 23,522 \\
ATVs & 138 & $4 \%$ & 73,927 & 15,122 \\
\hline ALL ORV & 763 & $20 \%$ & 497,403 & 68,887 \\
\hline \hline $\begin{array}{l}\text { ORNL's estimate of light trucks used } \\
\text { off-road at some time for recreational } \\
\text { purposes }\end{array}$ & & & 262,341 & \\
\hline
\end{tabular}




\subsection{Concluding Notes}

A direct comparison between state estimates and ORNL's estimates is still virtually impossible, despite the attempt to make these estimates as compatible as possible. As mentioned earlier, the total amount appropriated to the National Recreational Trails Trust Fund is authorized by the U.S. Department of Treasury on an annual basis. With a fixed amount of funding, FHWA faces the challenge of how to equitably apportion these funds to individual states based on the level of fuel used for off-road recreation. Two options are available to FHWA to address this challenge. The first one is to rely on the individual states to submit their annual estimates on off-highway recreational fuel use. The advantage of this option is that individual states could devote more resources to this activity, and can receive more cooperation in obtaining the data, than FHWA could. As a result, individual states might be able to produce more reliable estimates than FHWA could. However, more resources and more data do not guarantee more reliable estimates. The burden is then on the FHWA to verify the estimation methods employed by the individual states. This leads to two possible drawbacks if the first option is used. First, individual states have a great incentive to over-estimate their off-highway recreational fuel use. Second, the compatibility among states in estimating off-highway recreational fuel use becomes an enormous issue in trying to apportion the Trust Fund equitably. In addition, the third drawback of this option is that not every state submits the required estimate. In the 1992-1993 period, only twenty-three states did, and some of the estimates are for 1987 while others are for 1989 or 1990 (Table 7). Consequently, an estimation procedure would need to be developed for the remaining 22 states that failed to submit data, adding further complexity to the compatibility issue. 
To overcome the disadvantages of the first option, a second option for FHWA to meet its challenge is to "standardize" the estimation procedure and develop a common tool which can objectively apportion the National Recreational Trails Trust Funds on an annual basis. Two factors characterize this option: (1) individual state shares of the total Trust Funds need to be developed using a uniform approach, and (2) data needed for the estimation purpose should be publicly available and easily obtainable so that the FHWA can generate these estimates for all subsequent years. It is these two factors that govern the development of ORNL's estimation procedure discussed in this report. It is also because of these two factors that ORNL's estimates are recommended over individual states' estimates. Of course, this option is not without its drawbacks. One major drawback is the failure to take advantage of more detailed state-specific information.

\section{MOTORCYCLES AND ALL TERRAIN VEHICLES}

\subsection{Estimation Procedure}

Data on motorcycles and all terrain vehicles (ATVs) are extremely sparse. Two basic sources of off-highway motorcycle and ATV fuel consumption estimates are the Motorcycle Industry Council (MIC) and individual states. Several western states have conducted surveys of off-highway motorcycle fuel consumption. These state level studies were each performed with different survey practices and they reported a wide range of estimates. Studies from Arizona, California, Colorado, Oregon, Utah and Washington will be discussed later in Section 3.2.

The MIC has reported state vehicle population estimates annually since 1985. These estimates are divided into three vehicle model categories: highway, 
off-highway, and dual purpose. Since 1991, separate data were reported for ATVs. These state population estimates are computed by MIC from the annual retail sales of these vehicles in conjunction with the vehicle scrappage rates. Scrappage rates are based on user survey data. The accuracy of the resulting population estimate depends on the following factors: (1) the accuracy and coverage of state retail sales data, (2) the accuracy of the vehicle scrappage rates, and (3) the reasonableness of assuming zero net vehicle migration by vehicle vintage. Vehicle migration is the movement of vehicle registration from one state to the other. Even if the first two factors are correct, it might be reasonable to expect the migration issue to be problematic for southern and western states. From 1985 to 1990 , more than $11 \%$ of the population in the South and West Regions had migrated there from other states ${ }^{1}$ - the highest migration rate among all regions. Consequently, the MIC population estimates may have a downward bias for southern and western states.

The MIC also conducts periodic surveys of motorcycle and ATV usage. Unfortunately, this information is considered proprietary so that only limited access is permitted. The most recent 1990 survey covered 1,193 motorcycle and ATV owners in the United States. Further details regarding the survey method and the resulting response rate were not available. The distribution of annual miles driven is illustrated in Figure 1. This distribution is clearly skewed to the left with about $30 \%$ of the motorcycles and ATVs traveling 25 miles or less in the survey year. Using this survey information, the MIC estimated annual gasoline consumption to be 76 gallons per year. The method employed to obtain this estimate is summarized in Table 12. Since the MIC "believed the most accurate number for

1 Table No. 30. Statistical Abstract of the United States 1993. Bureau of the Census, U.S. Department of Commerce. 
estimating days ridden per year and gasoline use per day is the average of the mean and median," the last column of Table 12 presents the averages of the mean (Column 1) and the median (Column 2).

Figure 1. Average Miles Ridden in the Past 12 Months Off-the-Road

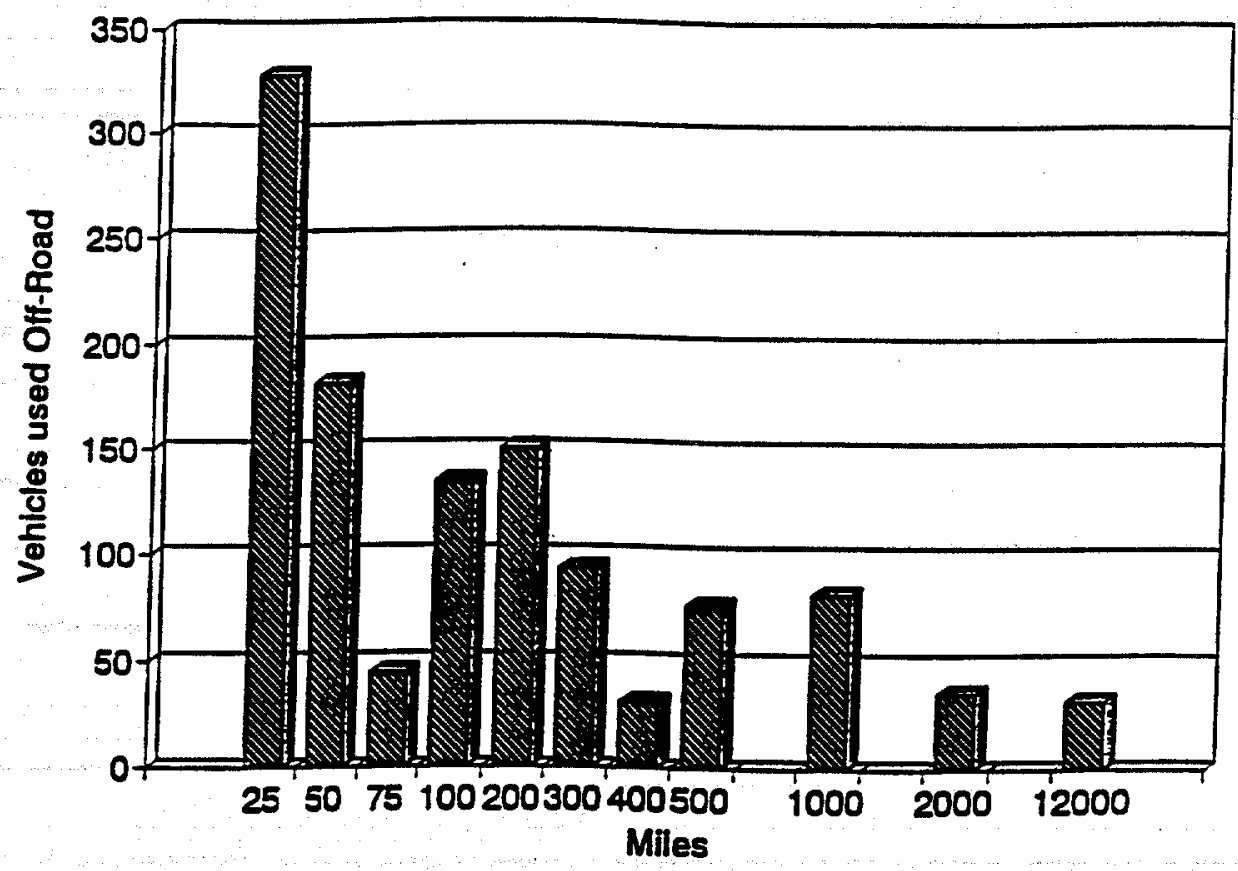

Source: 1990 Survey of Motorcycle Ownership and Usage. 
No reference is provided for this method of averaging the mean and median. Typically, the choice between the mean and median depends on prior information of the underlying distribution. If the distribution is thought to be normal or approximately normal, then the sample mean is the appropriate estimator. On the other hand, if the underlying distribution is Cauchy or nearly Cauchy, then the sample median is the appropriate estimator. When the underlying distribution is unknown, a "robust" estimator is preferable. This is an estimator which performs well for several different types of distributions, even though it may not be the best available for any particular distribution. Two such estimators proposed in the statistical literature are the "weighted mean" and the "trimmed mean", both of which yield the median estimate as a special case. Thus, when faced with evidence against a normal distribution, such as a large difference between mean and median, it may be advisable to use the median estimate over the mean estimate. This logic suggests that an estimate of 30 gallons per year for offhighway use may be more reasonable than either 76 or 143 gallons per year.

Table 12. MIC's Estimate of Annual Motorcycle Gasoline Consumption

\begin{tabular}{|c|c|c|c|}
\hline & $\begin{array}{c}\text { Mean } \\
(1)\end{array}$ & $\begin{array}{c}\text { Median } \\
(2)\end{array}$ & $\begin{array}{c}\text { MIC's } \\
\text { Estimates } \\
(3) \\
\end{array}$ \\
\hline $\begin{array}{l}\text { Average number of days ridden per year } \\
\text { off-highway } \\
\qquad \mathbf{x}\end{array}$ & 65 & 30 & 47.5 \\
\hline $\begin{array}{l}\text { Gallons of gasoline used per day } \\
\qquad=\end{array}$ & 2.2 & 1.0 & 1.6 \\
\hline $\begin{array}{l}\text { Gallons used annually per vehicle off- } \\
\text { highway }\end{array}$ & 143 & 30 & 76 \\
\hline
\end{tabular}

Source: 1990 Survey of Motorcycle Ownership and Usage. 
Using Equ. (1) to estimate the number of motorcycles and ATVs used offthe-road for recreational purposes, $c_{1}$ (the adjustment factor for unregistered vehicles) is assumed to be 1 . This is because the total number of motorcycles and ATVs estimated and reported by the MIC is a function of retail sales and has, supposedly, been adjusted for the number of unregistered vehicles. Since there is no state-specific information available on the percent time that a motorcycle or an ATV was used off-the-road, any vehicles that were used off-the-road at some time are enumerated. It was also assumed that whenever motorcycles were used off-theroad, they were for recreational purposes. Consequently, the adjustment factor for motorcycle's recreational use, $c_{3}$, is 1 . Based on these assumptions, data series on the number of motorcycles and ATVs used off-highway some of the time is the basis to calculate the amount of fuel used off-the-road for recreational purposes. It is recognized that this data series does not accurately represent the number of motorcycles and ATVs used off-the-road for recreational purposes as expressed in full-vehicle-equivalence. Until the time that state-specific information becomes available on the percentage of the time that motorcycles and ATVs are used offthe-road for recreational purposes, this data series is considered sufficient to meet the project's goals. The number of motorcycles used off-highway at some time in 1992 is estimated by MIC and presented in Table 13.

As mentioned earlier, starting in 1991, motorcycles and ATVs data are reported separately. Some results from the MIC's survey on ATVs permit additional refinements to estimates of the number of ATVs used off-the-road for recreational purposes. Based on the survey responses on the percentages of offroad riding for utility purposes, Table 14 presents estimates of the average percent time for which an ATV was used for off-the-road recreational purposes. It is assumed that riding off-the-road, that is not for utility purposes, is for recreational 
Table 13. Estimated Number of Motorcycles Used Off-Road for Recreational Purposes, 1992

\begin{tabular}{|c|c|c|c|}
\hline State & $\begin{array}{l}\text { Number of } \\
\text { Motorcycles }\end{array}$ & State & $\begin{array}{l}\text { Number of } \\
\text { Motorcycles }\end{array}$ \\
\hline (1401114. & 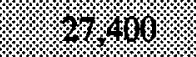 & (4) & 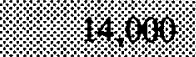 \\
\hline /4ing & 6696 & yorasista & $83 \% 3$ \\
\hline 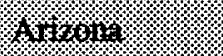 & (2) & 4yzr, & (x) \\
\hline \% & 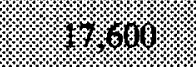 & 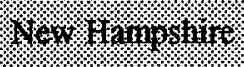 & 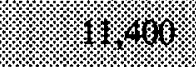 \\
\hline (6) & $203.18 \%$ & 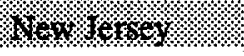 & 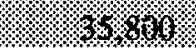 \\
\hline Colorado & 31,900 & New Mexico & 14,300 \\
\hline Connecticut & 18,100 & New York & 64,300 \\
\hline Delaware & 3,308 & North Carolina & 42,800 \\
\hline D. C. & 241 & North Dakota & 5,100 \\
\hline Florida & 70,517 & Ohio & 52,200 \\
\hline 6 & 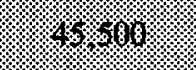 & (9) & 4. \\
\hline 4 & (1:- & orito & $4.1 \%$ \\
\hline 18.8ition: & 24.100 & 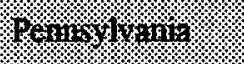 & $62 \%$ \\
\hline 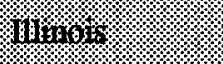 & 4.8 .896 & Rrinotralsining & $8 \%$ \\
\hline (in & 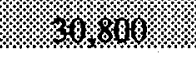 & 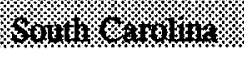 & $19 \% 26 \%$ \\
\hline Iowa & 16,200 & South Dakota & 5,500 \\
\hline Kansas & 12,300 & Tennessee & 32,800 \\
\hline Kentucky & 19,300 & Texas & 96,000 \\
\hline Louisiana & 16,800 & Utah & 24,300 \\
\hline Maine & 9,500 & Vermont & 4,100 \\
\hline 14n & 24,119 & 1119 mina & 36,280 \\
\hline 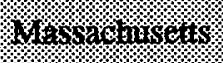 & $29,30 \%$ & Watingitin & $10 \%$ \\
\hline 4iriningin: & (5). & H. & (6) \\
\hline 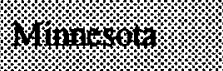 & 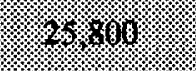 & $4 \%$ & 27000 \\
\hline 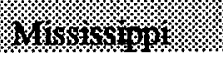 & 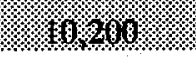 & 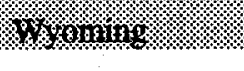 & 17,600 \\
\hline Missouri & 22,300 & & \\
\hline
\end{tabular}

Source: 1992 Motorcycle Statistical Anmual, Motorcycle Industry Council, Inc., Irvine, California. 
purposes. After adjusting for non-recreational uses, the number of ATVs used off-the-road for recreational purposes is calculated and given in Table 15.

Table 14. Average Percent of ATVs Off-the-Road Riding for Recreational Purposes

\begin{tabular}{|lc|}
\hline Region & $\begin{array}{c}\text { Percent of Off-the-road Riding for } \\
\text { Recreational Purposes }\end{array}$ \\
\hline East & 80.2 \\
Mid-West & 64.2 \\
South & 68.6 \\
West & 75.6 \\
\hline
\end{tabular}

Estimates from the MIC appear to reflect a high degree of uncertainty. Estimates of annual fuel consumption directly reported by the survey respondents were considered by the MIC to greatly underestimate actual fuel consumption. Nevertheless, these "underestimated" fuel uses and MIC's estimated annual miles driven imply an average fuel economy (MPG) of less than five -- significantly outside the range of the average motorcycle fuel economy of 35 to 75 .

\subsection{Synthesis of Average Motorcycle and ATV Fuel Use Estimates}

Unlike light trucks, there is no survey of motorcycles and ATVs that allows consistent estimates of annual fuel use by state. Several options were considered to estimate annual fuel use. These include: applying MIC's estimate to all states; using state estimates for states where individual state surveys were conducted and applying MIC's estimate to states for which no surveys were conducted; and taking 
Table 15. Estimated Number of ATVs Used Off-Road for Recreational Purposes, 1992

\begin{tabular}{|c|c|c|c|}
\hline State & $\begin{array}{c}\text { Number of } \\
\text { ATVs }\end{array}$ & State & $\begin{array}{c}\text { Number of } \\
\text { ATVs }\end{array}$ \\
\hline Natbanis: & 184.764 & 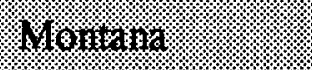 & 12.026 \\
\hline IIfastar & $20.2 \%$ & Herrofirat & 13.794 \\
\hline IIrivona & 26.624 & Nevara & 9.073 \\
\hline intransas: & .53 .586 & 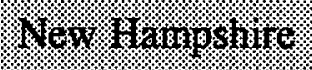 & (1). $394:$ \\
\hline Wealingrata: & $1.37,7.26$ & New lensey. & 22,869 \\
\hline Colorado & 16,262 & New Mexico & 9,455 \\
\hline Connecticut & 10,030 & New York & 63,953 \\
\hline Delaware & 3,619 & North Carolina & 42,639 \\
\hline D. C. & 0 & North Dakota & 5,774 \\
\hline Florida & 45,3111 & Ohio & 48.632 \\
\hline Georig: & 80.934. & Outanonar & 20.634 \\
\hline mavisin & & gregrn: & 19.8011 \\
\hline (y) & 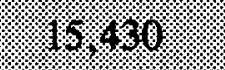 & 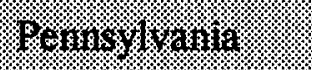 & $18.3587:$ \\
\hline Whors: & 29.5319. & Rinode Iriand & $.1 .3 \%$ \\
\hline Mnatiasia & $30,30.26$ & Sorth I Carolina & $16,04:$ \\
\hline Iowa & 16,617 & South Dakota & 6,352 \\
\hline Kansas & 11,548 & Tennessee & 50,249 \\
\hline Kentucky & 29,477 & Texas & 77,601 \\
\hline Louisiana & 44,764 & Utah & 24,128 \\
\hline Maine & 15,005 & Vermont & 64419 \\
\hline 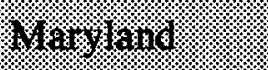 & 1.9 .908$. & 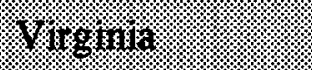 & 26.7 .785 \\
\hline 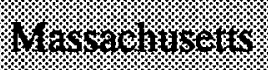 & $(15.127 \%$ & Whatingen & 26,094 \\
\hline Michigan:-s: & $68 \div 886$ & Hest. Uinging & 81.782 \\
\hline 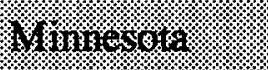 & 35.9 .90 & Hiscrensinil: & 31248 \\
\hline Mississisiplat & $34,8,2$ & Wyoning & (1,, $36 \%$ \\
\hline Missouri & 39,521 & & \\
\hline
\end{tabular}


advantage of all available estimates to derive a synthesized estimate. Since every survey has strengths and limitations, the last option of synthesizing all available estimates appears to be the most desirable.

In addition to the MIC's periodic surveys of motorcycle and ATV usage, six states have conducted surveys to estimate the number of off-road vehicles and fuel consumption. They are Arizona, California, Colorado, Oregon, Utah and Washington. These estimates are generated using very different approaches, with various limitations. To synthesize these estimates, a detailed evaluation of MIC survey and individual state surveys is imperative in order to obtain a set of subjective weights, one weight for each estimate. Estimates that are generated from more thorough surveys are given higher weights than those generated from less thorough approaches.

In general, all of the state studies estimated total gasoline consumption as the product of the estimated vehicle population and the annual gallons consumed per vehicle off-road for recreational purposes. However, a number of different approaches were used to estimate the annual fuel consumption per vehicle for offroad recreational purposes. The direct approach of simply using the survey respondents' estimates of total annual fuel used was typically not employed. Instead, the average annual fuel use for off-road recreational purposes was frequently estimated as: 


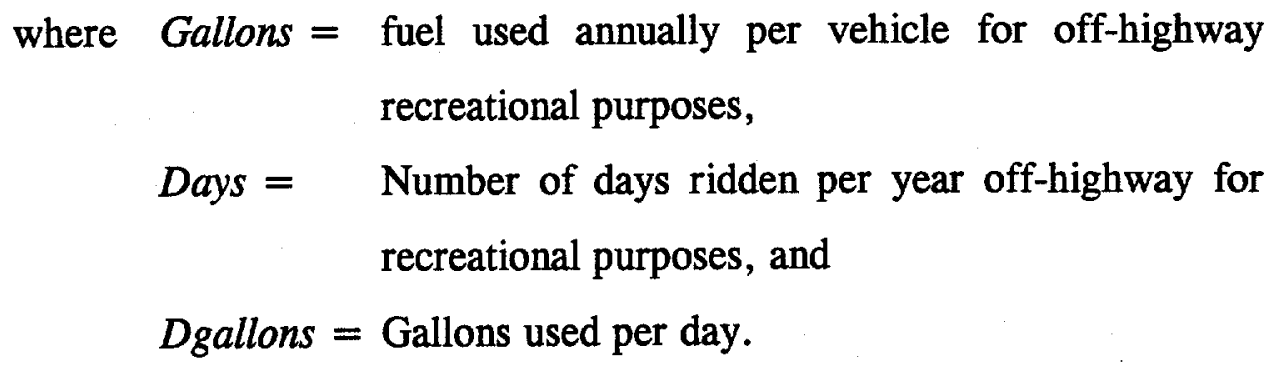

The stated reason for using this rather indirect approach is that the survey respondents were likely to underestimate the total annual fuel use. It was further suggested that a better estimate of total annual fuel use can be obtained from the survey respondents by asking for an estimate of the number of days ridden per year for off-highway recreational purposes and the average amount of fuel used per day, rather than by asking for the total annual fuel use directly. No related studies were cited to support this hypothesized survey response bias.

Consider the mathematical expression,

$$
E(\text { Gallons })=E(\text { Days }) \times E(\text { Dgallons })+\operatorname{Cov}(\text { Days, Dgallons })
$$

where $E$ is the expectation operator. There is no reason to believe a priori that Days and Dgallons are uncorrelated (i.e., Cov (Days, Dgallons) =0). Instead, one of two approaches is preferable to compute a representative summary measure such as the mean or the median. One approach is to compute the mean or the median of the direct survey responses on the total annual fuel use. The other approach is to compute the mean or the median of the product of Days and Dgallons [i.e., Mean(Days $\times$ Dgallons)].

In the following section, states' estimates of the number of off-highway motorcycles and their fuel use are examined in more detail. The diversity in 
survey methods contributes to a large degree the wide variation in states' estimates of the average annual fuel use of off-highway motorcycles. Since comprehensive survey practices are very expensive, many of the state's survey efforts are limited. For example, only one state, California, attempted to estimate the use of unregistered vehicles. Most of the other states based their estimates on the number of registered vehicles, while some used an assumed correction factor to include unregistered vehicles. Although many of the state's off-highway vehicle surveys were discussed in Section 2.2, for completeness, these surveys are repeated here.

\section{Arizona}

Two different surveys were conducted - one for the winter and one for the summer season. Each survey covered a six month period and contacted 1,000 households using a random dialing procedure that selected a number of telephone numbers in proportion to each county's population size. A low response rate in the initial contacts led to additional phone calls. Overall, 331 households indicated that they had driven their off-road vehicles off-highway during the six-month sample period in the Winter of 1989, and 353 households indicated that they had driven their off-road vehicles off-highway during the six-month sample period in the Summer of 1990 . The reported survey results do not include any usage information by vehicle class. However, the results provide some useful information for the estimates of the number of motorcycles and ATVs used for offthe-road recreational purposes which are summarized in Table 16.

The large variation in total population estimates for motorcycles and ATVs between the two surveys indicates that a relatively large standard error is associated with these estimates. A comparison of the combined average of these two estimates, labeled "Motorcycles \& ATVs (based on survey average)", with the 
Table 16. Estimated Number of Arizona Motorcycles and ATVs Used Off-Highway (Based on results from the 1990 Arizona Off-Highway Vehicle Survey)

\begin{tabular}{||l|c|c||}
\hline & $\begin{array}{c}\text { Estimated Total } \\
\text { Vehicle Population }\end{array}$ & $\begin{array}{c}\text { Estimated Off-road } \\
\text { Vehicle Population }\end{array}$ \\
\hline $\begin{array}{l}\text { Motorcycles } \\
\text { (Based on the Winter Survey) }\end{array}$ & 154,455 & 36,287 \\
\hline $\begin{array}{l}\text { Motorcycles } \\
\text { (Based on the Summer Survey) }\end{array}$ & 98,532 & 23,921 \\
\hline $\begin{array}{l}\text { Motorcycles } \\
\text { (Survey Average) }\end{array}$ & 126,494 & 30,104 \\
\hline $\begin{array}{l}\text { ATVs } \\
\text { (Based on the Winter Survey) }\end{array}$ & 83,885 & 27,748 \\
\hline $\begin{array}{l}\text { ATVs } \\
\text { (Based on the Summer Survey) }\end{array}$ & 59,918 & 18,847 \\
\hline $\begin{array}{l}\text { ATVs } \\
\text { (Survey Average) }\end{array}$ & 71,902 & 23,298 \\
\hline $\begin{array}{l}\text { Motorcycles \& ATVs } \\
\text { (Survey Average) }\end{array}$ & 104,400 & 53,402 \\
\hline $\begin{array}{l}\text { Motorcycles \& ATVs } \\
\text { (Based on Arizona's DOT) }\end{array}$ & 75,547 & \\
\hline Motorcycles \& ATVs & & \\
\hline (Based on MIC) & & \\
\hline
\end{tabular}


number of registered motorcycles and ATVs reported by the Arizona Department of Transportation yields an approximate estimate of the number of unregistered vehicles. The correction factor for unregistered vehicles, the ratio of unregistered to registered vehicles, is about $1.6[(198,395$ - 75,547$) / 75,547]$-- an estimate several times smaller than that reported by California (to be discussed later). It is also interesting to note that $71 \%$ of the registered vehicles are used off-the-road $(53,402 / 75,547=0.71)$. The corresponding MIC estimate of the total motorcycles and ATVs population for the State of Arizona is only 52\% $(104,400 / 198,395=0.52)$. This large discrepancy is hard to explain with just the vehicle migration issue, as discussed in Section 3.1, associated with the MIC vehicle population estimates.

\section{California}

A randomly selected sample of 20,394 households were contacted. Of those, 12,156 surveys were completed, yielding a response rate of almost $60 \%$. The sample covered 53 of California's 58 counties. The sample was selected in proportion to each county's population size. The 5 counties which were not covered in the survey each represents no more than one-tenth of one percent of the state's total population. All panelists were interviewed four times, once every three months. Each respondent was sent a reminder postcard that notified him/her when he/she would be contacted (or re-contacted). Each respondent was also provided a diary to keep track of his/her off-road fuel use. The registration status of each vehicle sampled was determined by matching the sampled vehicles with California's Department of Motor Vehicles' registration file of off-highway vehicles. Based on the matching results, a correction factor was computed to estimate the total number (registered and unregistered vehicles) of off-road vehicles of a particular class. This correction factor was 1 plus the ratio of unregistered 
vehicles to registered vehicles. A summary of the survey results are presented in Table 17.

The reported estimate of annual fuel use is the product of the monthly fuel consumption estimates and the monthly usage estimates summed over the year 1989. Compared to other states' and MIC's estimates, California's estimates are among the lowest in this summary of off-road fuel consumption studies. However, the correction factor for unregistered vehicle seems surprisingly high for motorcycles, a ratio of six to one. This correction factor was based on an observation of 521 vehicles of which only 76 could be matched with DMV records. Any problems with this matching process could easily result in an over- or (under-) estimate of the ratio of unregistered vehicles to registered vehicles. Table 17 also shows the resulting estimate of the off-road motorcycle population which is over four and a half times that of the MIC estimates. Clearly, the difference is difficult to account for, short of an overly high correction factor for unregistered vehicles.

\section{Colorado}

A mail survey was done of randomly-selected registered off-road vehicles. Unfortunately, documentation of survey results is virtually non-existent. Since no information is available regarding the important factors, such as the number of households surveyed or the response rate, etc., no assessment is made of the survey results. A summary of the reported results are presented in Table 18.

The total number of vehicles was derived based on an assumption that half of all off-highway motorcycles, half of all ATVs, and ninety percent of all snowmobiles are registered. The fuel usage estimates are also very conservative, and in line with those of California. 


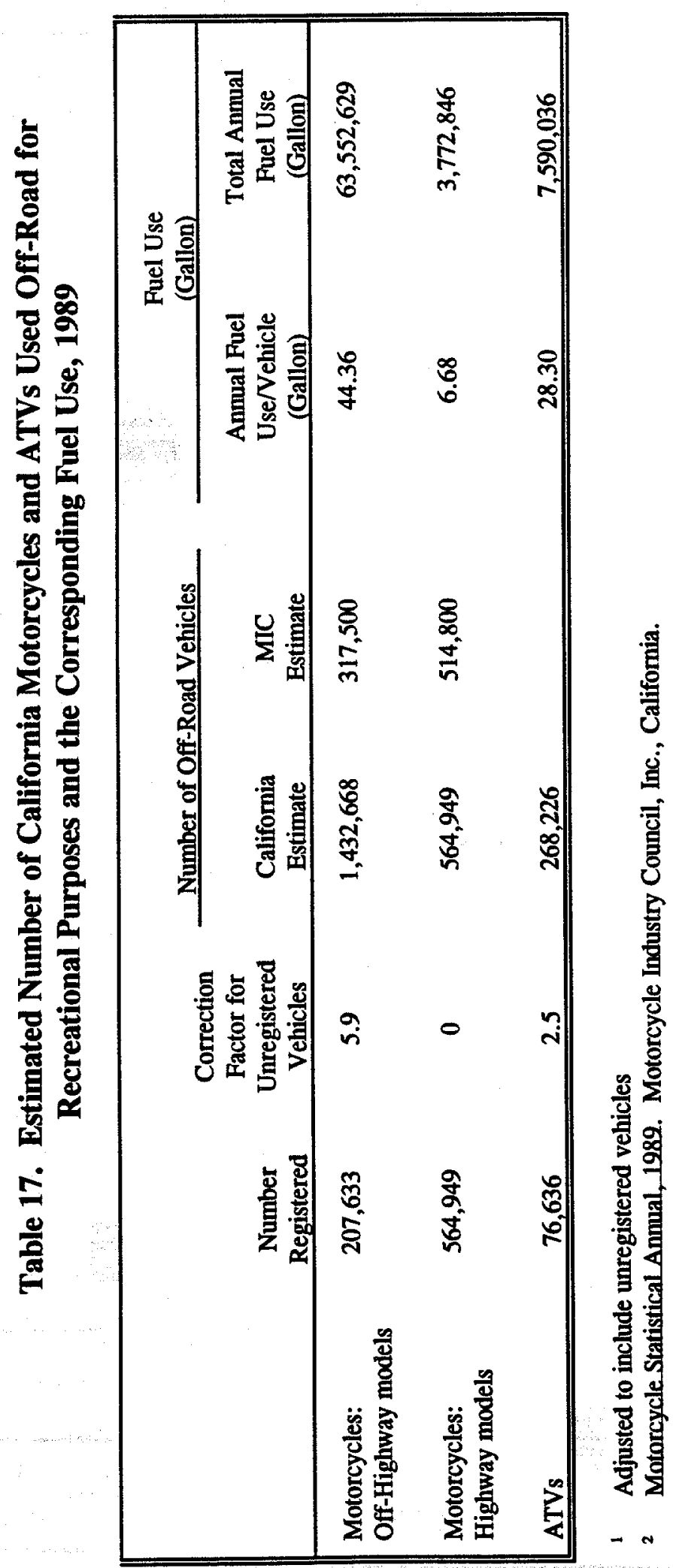




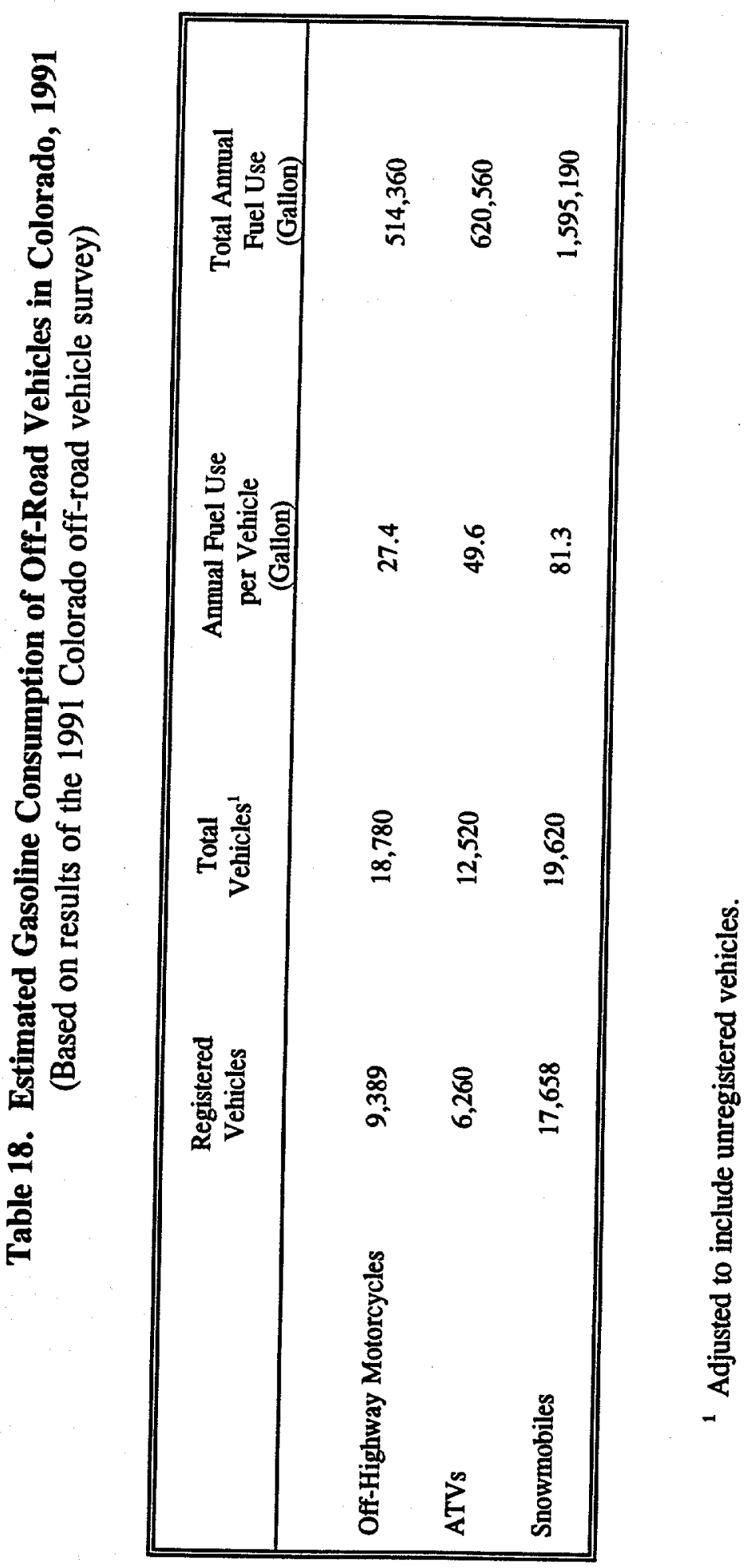




\section{Oregon}

An off-road vehicle use survey was conducted on randomly-selected registered off-road vehicles. No effort was made to survey non-registered vehicles. A summary of the relevant survey results is present in Table 10 .

Not including incomplete responses, the survey response rate was about $70 \%$, which is reasonably good for a voluntary survey. Unfortunately, the results may not be very representative of all off-highway motorcycle owners in that half of the working sample consists of new vehicle owners. These new owners are likely to use their new vehicles more intensively than other owners. This problem is not as pronounced with ATVs in that only $17 \%$ of the sampled ATV owners may be new (i.e., owning the vehicle less than a year) (Table 10). These annual fuel consumption estimates illustrate the difference between consumption estimates reported directly by survey respondents and estimates computed by Days and Gallons. The fact that the average of the product of Days and Gallons [Mean(Days $\times$ Gallons)] is greater than the product of the averages [Mean(Days) $x$ Mean(Gallons)] indicates that Days and Gallons are positively correlated across individuals. Furthermore, as mentioned earlier, there is no supporting evidence to believe that Mean(Days $\times$ Gallons) is a better estimate than the annual fuel use reported directly by the survey respondents. After an adjustment for recreational use, the estimates for both ATVs and $4 \times 4 \mathrm{~s}$ in Table 10 are substantially lower than the unadjusted numbers.

\section{Utah}

A telephone survey of registered off-road vehicle owners was performed for a 1990 off-road vehicle usage study. This survey contacted over 1,000 owners, of whom 600 completed questionnaires. No attempt was made to estimate the number of unregistered vehicles or to estimate non-recreational use. The survey 
specifically asked about the total gallons of fuel purchased for off-road vehicles. The overall fuel use for off-road vehicles is reported to be 331 gallons per household. Unfortunately, tabulations of the survey results did not include average annual fuel consumption by vehicle class. The results of this survey are, therefore, of limited value to this study.

\section{Washington}

A telephone survey of 3,460 households was conducted in 1986 regarding off-road recreational vehicle usage in 1985. The method that was used to select telephone numbers is not documented. The sample size within each district was proportional to the population of the counties making up the district. The survey identified 763 households owning one or more off-road vehicles (ORV). The parameters at the state level were estimated by proportionally weighting the survey results by the sampling expansion factors. These estimates together with other relevant statistics are reported in Table 11. Also reported in Table 11 is a confidence range with an unspecified significance level. A comparison with MIC's 1985 estimates of the number of off-road motorcycles and ATVs yields a large difference which is over four times the reported confidence range.

A follow up mail survey was also conducted with the owners identified in the telephone survey. Unfortunately, only $34 \%$ of these households returned a completed survey. Only $2 \%$ of both dirt bike and ATV owners did not use their vehicles at all in 1985, whereas $14 \%$ of dirt bike owners and $25 \%$ of ATV owners used their vehicles over one hundred days in 1985 . The survey did not include any questions regarding fuel consumption. Results from this mail survey are most likely not representative due to selection bias. 


\section{Comparison_Summary}

Estimates of the annual fuel consumption per off-road motorcycle (or ATV) from four states (California, Colorado, Oregon and Washington) and the MIC are summarized in Table 19. As discussed previously, the MIC estimate was calculated as:

$$
\begin{aligned}
& \frac{\text { Mean (Days) }+ \text { Median(Days) }}{2} \times \frac{(\text { Means(Dgallons })+\text { Median(Dgallons })}{2} \\
& =76 \text { gallons per year }
\end{aligned}
$$

Unless it can be proved that Days and Dgallons are uncorrelated (i.e., Cov (Days, Dgallons $)=0$ ), a more accurate estimate of annual fuel use could have been calculated as:

Mean (Days $\times$ Dgallons) or Median(Days $\times$ Dgallons $)$

or as:

Mean(Gallons) or Median(Gallons)

where Days = the number of days ridden per year off-highway for recreational purposes,

Dgallons $=$ the amount of fuel used per day ridden off-highway for recreational purposes, and

Gallons = the estimated annual fuel used per vehicle ridden offhighway for recreational purposes.

The resulting estimates vary considerably depending on which method is employed. Without the actual survey data, these more accurate estimates of annual fuel use can not be calculated. 
Table 19. Comparison of Annual Fuel Use per Off-Highway Motorcycle and ATV (Based on four State surveys and the MIC survey)

\begin{tabular}{||l|c||c|c||c|c||}
\hline \multirow{2}{*}{ Source } & \multicolumn{2}{|c|}{$\begin{array}{c}\text { Sample } \\
\text { Size }\end{array}$} & \multicolumn{2}{|c||}{ Annual Fuel Use/Vehicle } & \multicolumn{2}{|c|}{ Total Annual Miles/Vehicle } \\
\cline { 3 - 6 } & Motorcycles & ATVs & Motorcycles & ATVs \\
\hline MIC & 1,193 & 76.0 & 76.0 & 353 & 353 \\
California & 754 & 44.4 & 28.3 & - & - \\
Colorado & $?$ & 27.4 & 49.6 & - & - \\
Oregon & 721 & 89.3 & 125.6 & - & - \\
Washington & 282 & - & - & 2,700 & 3,360 \\
\hline
\end{tabular}

The California estimates appear to be carefully developed. A multiplesurvey effort with a usage diary is a better method of obtaining annual fuel consumption estimates than using the product of the number of days riding offhighway per year and the amount of fuel used per day. California's estimates are considerably lower than those reported by the MIC.

The Colorado estimates are also reasonably low but are basically undocumented. It is difficult, therefore, to give these estimates much weight in formulating an overall summary measure.

The Oregon estimates are the highest in this review of off-highway vehicle studies. The motorcycle estimate is likely to be biased upwardly because of the large proportion of new motorcycle owners, $50 \%$. The ATV estimate is also quite large but may be reasonably representative in that only $17 \%$ of the sampled ATV owners were new owners and that the survey response rate was almost $70 \%$. However, the large proportion of vehicles which were not used for recreational 
purposes, $25 \%$, was not properly accounted for in the final estimation, resulting in a large over-estimation of the final state totals.

The Washington survey, which did not collect fuel consumption information, reports very high annual mileage. With a response rate of only $30 \%$, selection bias is likely to be strong. Consequently, the value of this survey is limited for the purpose of our study.

Based on these available estimates, the following combined estimates are formulated. The high and low ranges in Table 20 appear reasonable given the wide variation in available estimates. The subjective weights are based on the above assessments. A higher subjective weight is given to an estimate from an approach that is more reliable for the purpose of our study. Based on these weighted averages of annual fuel use, three sets of estimates are calculated for each vehicle class. One set is based on the low fuel use estimate, one on the high fuel use estimate, and the third one on the average of the low and high estimates. Tables 21 and 22 present the estimated number of vehicles used off-highway at some time for recreational purposes, and the amount of fuel used by motorcycles and ATVs for off-the-road recreational purposes, respectively.

State population estimates of off-highway vehicles also exhibit considerable variation. A summary of these estimates is provided in Table 23. Estimates for both Colorado and Oregon are lower than other states' estimates for the following reason. These state estimates are both based on the number of registered vehicles with no attempt to estimate the number of unregistered vehicles. On the other hand, Arizona, California, and Washington all attempt to estimate the number of unregistered vehicles by means of a survey. The California survey did not have a vehicle registration status question, and instead relied on matching the 
Table 20. Subjective Weights and Weighted Average Annual Fuel Consumption per Off-Highway Motorcycle and ATV

\begin{tabular}{||l|c|c||}
\hline \multirow{2}{*}{} & \multicolumn{2}{|c|}{ Subjective Weights } \\
\cline { 2 - 3 } & Low & High \\
\hline California & $75.0 \%$ & $50 \%$ \\
\hline Oregon & $12.5 \%$ & $25 \%$ \\
\hline MIC & $12.5 \%$ & $25 \%$ \\
\hline Motorcycles & 54 & 64 \\
\hline ATVs & 46 & 65 \\
\hline
\end{tabular}

Department of Motor Vehicles' records. This approach may in part account for the large difference from the corresponding MIC estimate. In any case, the large differences between the state's estimates and the MIC's corresponding estimates for Arizona and Washington are difficult to explain. Even after adjusting the MIC estimates to allow a positive net vehicle migration and to have slower depreciation rates, at most only $30 \%$ of these differences may be accounted for. The remaining difference might be attributable to:

1. limitations in states' survey sampling methods, and

2 . inaccuracy in MIC's annual retail sales.

Without additional information, it is not possible to resolve the differences between the states' and MIC's estimates at this time. It is therefore recommended that the MIC's estimates continue to be used in estimation of state number of motorcycles and ATVs used for off-highway recreational purposes. 
Table 21. Estimated Number of Motorcycles Used off the Road for Recreational Purposes and the Corresponding Fuel Consumption - 1992

\begin{tabular}{|l|c|r|r|r||}
\hline & & \multicolumn{3}{|c|}{ Fuel Used (Gallon) } \\
\cline { 3 - 5 } State & Number of & $\begin{array}{c}\text { Low } \\
\text { Vestimates }\end{array}$ & $\begin{array}{c}\text { Average } \\
\text { Estimates }^{2}\end{array}$ & $\begin{array}{c}\text { High } \\
\text { Estimates }\end{array}$ \\
\hline Alabama & 27,400 & $1,479,600$ & $1,616,600$ & $1,753,600$ \\
Alaska & 6,000 & 324,000 & 354,000 & 384,000 \\
Arizona & 25,100 & $1,355,400$ & $1,480,900$ & $1,606,400$ \\
Arkansas & 17,600 & 950,400 & $1,038,400$ & $1,126,400$ \\
California & 253,754 & $13,702,730$ & $14,971,500$ & $16,240,270$ \\
Colorado & 31,900 & $1,722,600$ & $1,882,100$ & $2,041,600$ \\
Connecticut & 18,100 & 977,400 & $1,067,900$ & $1,158,400$ \\
Delaware & 3,308 & 178,618 & 195,156 & 211,695 \\
D. C. & 241 & 13,038 & 14,246 & 15,453 \\
Florida & 70,517 & $3,807,897$ & $4,160,480$ & $4,513,063$ \\
Georgia & 45,500 & $2,457,000$ & $2,684,500$ & $2,912,000$ \\
Hawaii & 4 & 4 & 4 & 4 \\
Idaho & 24,100 & $1,301,400$ & $1,421,900$ & $1,542,400$ \\
Illinois & 45,000 & $2,430,000$ & $2,655,000$ & $2,880,000$ \\
Indiana & 30,800 & $1,663,200$ & $1,817,200$ & $1,971,200$ \\
Iowa & 16,200 & 874,800 & 955,800 & $1,036,800$ \\
Kansas & 12,300 & 664,200 & 725,700 & 787,200 \\
Kentucky & 19,300 & $1,042,200$ & $1,138,700$ & $1,235,200$ \\
Louisiana & 16,800 & 907,200 & 991,200 & $1,075,200$ \\
Maine & 9,500 & 513,000 & 560,500 & 608,000 \\
Maryland & 24,400 & $1,317,600$ & $1,439,600$ & $1,561,600$ \\
Massachusetts & 29,300 & $1,582,200$ & $1,728,700$ & $1,875,200$ \\
Michigan & 52,500 & $2,835,000$ & $3,097,500$ & $3,360,000$ \\
Minnesota & 25,800 & $1,393,200$ & $1,522,200$ & $1,651,200$ \\
Mississippi & 10,200 & 550,800 & 601,800 & 652,800 \\
Missouri & 22,300 & $1,204,200$ & $1,315,700$ & $1,427,200$ \\
\hline
\end{tabular}

${ }^{1}$ Estimates are based on 54 gallons per vehicle.

${ }^{2}$ Estimates are based on 59 gallons per vehicle.

${ }^{3}$ Estimates are based on 64 gallons per vehicle.

${ }^{4}$ Motorcycle data for Hawaii are not available. 


\begin{tabular}{|c|c|c|c|c|}
\hline \multirow[b]{2}{*}{ State } & \multirow[b]{2}{*}{$\begin{array}{l}\text { Number of } \\
\text { Vehicles }\end{array}$} & \multicolumn{3}{|c|}{ Fuel Used (Gallon) } \\
\hline & & $\begin{array}{c}\text { Low } \\
\text { Estimates }^{1}\end{array}$ & $\begin{array}{c}\text { Average } \\
\text { Estimates }^{2}\end{array}$ & $\underset{\text { Estimates }^{3}}{\text { High }}$ \\
\hline Montana & 14,000 & 756,000 & 826,000 & 896,000 \\
\hline Nebraska & 8,300 & 448,200 & 489,700 & 531,200 \\
\hline Nevada & 13,396 & 723,369 & 790,348 & 857,326 \\
\hline New & 11,400 & 615,600 & 672,600 & 729,600 \\
\hline New Jersey & 35,800 & $1,933,200$ & $2,112,200$ & $2,291,200$ \\
\hline New Mexico & 14,300 & 772,200 & 843,700 & 915,200 \\
\hline New York & 64,300 & $3,472,200$ & $3,793,700$ & $4,115,200$ \\
\hline North & 42,800 & $2,311,200$ & $2,525,200$ & $2,739,200$ \\
\hline North Dakota & 5,100 & 275,400 & 300,900 & 326,400 \\
\hline Ohio & 52,200 & $2,818,800$ & $3,079,800$ & $3,340,800$ \\
\hline Oklahoma & 26,100 & $1,409,400$ & $1,539,900$ & $1,670,400$ \\
\hline Oregon & 31,223 & $1,686,028$ & 1842141 & $1,998,255$ \\
\hline Pennsylvania & 62,200 & $3,358,800$ & $3,669,800$ & $3,980,800$ \\
\hline Rhode Island & 5,000 & 270,000 & 295,000 & 320,000 \\
\hline South & 19,200 & $1,036,800$ & $1,132,800$ & $1,228,800$ \\
\hline South Dakota & 5,500 & 297,000 & 324,500 & 352,000 \\
\hline Tennessee & 32,800 & $1,771,200$ & $1,935,200$ & $2,099,200$ \\
\hline Texas & 96,000 & $5,184,001$ & $5,664,001$ & $6,144,001$ \\
\hline Utah & 24,300 & $1,312,200$ & $1,433,700$ & $1,555,200$ \\
\hline Vermont & 4,100 & 221,400 & 241,900 & 262,400 \\
\hline Virginia & 36,200 & $1,954,800$ & $2,135,800$ & $2,316,800$ \\
\hline Washington & 50,700 & $2,737,800$ & $2,991,300$ & $3,244,800$ \\
\hline West Virginia & 16,700 & 901,800 & 985,300 & $1,068,800$ \\
\hline Wisconsin & 27,000 & $1,458,000$ & $1,593,000$ & $1,728,000$ \\
\hline Wyoming & 7,000 & 378,000 & 413,000 & 448,000 \\
\hline TOTAL & $1,543,539$ & $83,351,081$ & $91,068,772$ & $98,786,463$ \\
\hline
\end{tabular}

${ }^{1}$ Estimates are based on 54 gallons per vehicle.

${ }^{2}$ Estimates are based on 59 gallons per vehicle.

${ }^{3}$ Estimates are based on 64 gallons per vehicle. 
Fuel Used for Off-Highway Recreation $-57-$

Table 22. Estimated Number of ATVs Used off the Road for Recreational Purposes and the Corresponding Fuel Consumption - 1992

\begin{tabular}{|l|c|r|r|r||}
\hline & & \multicolumn{3}{|c|}{ Fuel Used (Gallon) } \\
\cline { 3 - 5 } State & Number of & $\begin{array}{c}\text { Low } \\
\text { Estimates }\end{array}$ & $\begin{array}{c}\text { Average } \\
\text { Estimates }^{2}\end{array}$ & $\begin{array}{c}\text { High } \\
\text { Estimates }^{3}\end{array}$ \\
\hline Alabama & 44,764 & $2,059,165$ & $2,484,427$ & $2,909,690$ \\
Alaska & 20,270 & 932,441 & $1,125,010$ & $1,317,579$ \\
Arizona & 26,624 & $1,224,698$ & $1,477,625$ & $1,730,552$ \\
Arkansas & 55,596 & $2,557,401$ & $3,085,560$ & $3,613,719$ \\
California & 137,720 & $6,335,115$ & $7,643,454$ & $8,951,793$ \\
Colorado & 16,262 & 748,040 & 902,527 & $1,057,013$ \\
Connecticut & 10,030 & 461,392 & 556,679 & 651,966 \\
Delaware & 3,619 & 166,490 & 200,874 & 235,258 \\
D. C. & 0 & 0 & 0 & 0 \\
Florida & 45,311 & $2,084,290$ & $2,514,742$ & $2,945,193$ \\
Georgia & 50,934 & $2,342,970$ & $2,826,845$ & $3,310,719$ \\
Hawaii & 4 & 4 & 4 & 4 \\
Idaho & 15,430 & 709,768 & 856,351 & $1,002,933$ \\
Illinois & 29,513 & $1,357,583$ & $1,637,954$ & $1,918,324$ \\
Indiana & 30,026 & $1,381,193$ & $1,666,440$ & $1,951,686$ \\
Iowa & 16,617 & 764,378 & 922,239 & $1,080,100$ \\
Kansas & 11,548 & 531,228 & 640,938 & 750,649 \\
Kentucky & 29,477 & $1,355,959$ & $1,635,994$ & $1,916,028$ \\
Louisiana & 44,764 & $2,059,165$ & $2,484,427$ & $2,909,690$ \\
Maine & 15,005 & 690,242 & 832,792 & 975,342 \\
Maryland & 15,968 & 734,535 & 886,233 & $1,037,930$ \\
Massachusetts & 15,727 & 723,462 & 872,873 & $1,022,283$ \\
Michigan & 68,906 & $3,169,662$ & $3,824,266$ & $4,478,870$ \\
Minnesota & 35,159 & $1,617,295$ & $1,951,302$ & $2,285,308$ \\
Mississippi & 34,002 & $1,564,082$ & $1,887,099$ & $2,210,116$ \\
Missouri & 39,521 & $1,817,981$ & $2,193,434$ & $2,568,886$ \\
Montana & 12,026 & 553,202 & 667,450 & 781,698 \\
Nehraska & 13,794 & 634,523 & 765,565 & 896,608 \\
\hline
\end{tabular}

${ }^{1}$ Estimates are based on 46 gallons per vehicle.

${ }^{2}$ Estimates are based on 55.5 gallons per vehicle.

${ }^{3}$ Estimates are based on 65 gallons per vehicle.

${ }^{4}$ ATVs data for Hawaii state are not available. 


\begin{tabular}{|c|c|c|c|c|}
\hline \multirow[b]{2}{*}{ State } & \multirow[b]{2}{*}{$\begin{array}{c}\text { Number of } \\
\text { Vehicles }\end{array}$} & \multicolumn{3}{|c|}{ Fuel Used (Gallon) } \\
\hline & & $\begin{array}{c}\text { Low } \\
\text { Estimates }^{1}\end{array}$ & $\begin{array}{c}\text { Average } \\
\text { Estimates }^{2}\end{array}$ & $\begin{array}{c}\text { High } \\
\text { Estimates }^{3}\end{array}$ \\
\hline Nevada & 9,073 & 417,378 & 503,575 & 589,773 \\
\hline New Hampshire & 11,394 & 524,141 & 632,387 & 740,634 \\
\hline New Jersey & 22,869 & $1,051,973$ & $1,269,228$ & $1,486,483$ \\
\hline New Mexico & 9,455 & 434,907 & 524,725 & 614,543 \\
\hline New York & 63,953 & $2,941,832$ & $3,549,385$ & $4,156,937$ \\
\hline North Carolina & 42,639 & $1,961,410$ & $2,366,484$ & $2,771,557$ \\
\hline North Dakota & 5,774 & 265,614 & 320,469 & 375,324 \\
\hline Ohio & 48,632 & $2,237,061$ & $2,699,063$ & $3,161,065$ \\
\hline Oklahoma & 20,634 & 949,171 & $1,145,196$ & $1,341,220$ \\
\hline Oregon & 29,671 & $1,364,862$ & $1,646,736$ & $1,928,609$ \\
\hline Pennsylvania & 78,557 & $3,613,619$ & $4,359,909$ & $5,106,200$ \\
\hline Rhode Island & 1,525 & 70,132 & 84,615 & 99,099 \\
\hline South Carolina & 16,041 & 737,894 & 890,285 & $1,042,676$ \\
\hline South Dakota & 6,352 & 292,176 & 352,516 & 412,857 \\
\hline Tennessee & 50,249 & $2,311,437$ & $2,788,798$ & $3,266,160$ \\
\hline Texas & 77,601 & $3,569,640$ & $4,306,848$ & $5,044,056$ \\
\hline Utah & 24,128 & $1,109,883$ & $1,339,098$ & $1,568,313$ \\
\hline Vermont & 6,419 & 295,291 & 356,274 & 417,258 \\
\hline Virginia & 26,735 & $1,229,823$ & $1,483,808$ & $1,737,793$ \\
\hline Washington & 26,094 & $1,200,343$ & $1,448,240$ & $1,696,137$ \\
\hline West Virginia & 33,782 & $1,553,967$ & $1,874,895$ & $2,195,823$ \\
\hline Wisconsin & 31,245 & $1,437,267$ & $1,734,094$ & $2,030,921$ \\
\hline Wyoming & 7,337 & 337,488 & 407,186 & 476,885 \\
\hline TOTAL & $1,488,772$ & $68,483,569$ & $82,626,914$ & $96,770,256$ \\
\hline
\end{tabular}

${ }^{1}$ Estimates are based on 46 gallons per vehicle.

${ }^{2}$ Estimates are based on 55.5 gallons per vehicle.

${ }^{3}$ Estimates are based on 65 gallons per vehicle. 
Table 23. Comparison Summary of States' Estimates of Total Number of Off-Highway Motorcycles and ATVs

(Based on State Surveys)

\begin{tabular}{||l|c|c|c||}
\hline & $\begin{array}{c}\text { State } \\
\text { Estimate }\end{array}$ & $\begin{array}{c}\text { MIC } \\
\text { Estimate }\end{array}$ & $\begin{array}{c}\text { Ratio } \\
\text { (State/MIC) }\end{array}$ \\
\hline Arizona & 198,395 & 104,400 & 1.9 \\
\hline California & $1,700,894$ & 317,500 & 5.4 \\
\hline Colorado & 31,300 & 50,200 & 0.6 \\
\hline Oregon & 42,700 & 67,500 & 0.6 \\
\hline Washington & 269,667 & 103,900 & 2.6 \\
\hline
\end{tabular}

\section{SNOWMOBILES}

\subsection{Estimation Procedure}

Since 1981, thirty-one states have been submitting their snowmobile registration data to the International Snowmobile Industry Association (ISIA) in response to ISIA's annual registration survey - North American Snowmobile Registration Survey. Table 24 reports snowmobile registration data by state. In this estimation procedure, all snowmobiles are assumed to be used exclusively offthe-road, implying that $c_{2}$ in Equation (1) equals 1. Until state-specific information on the percentage of the time when a snowmobile is used for non-recreational purposes becomes available, the factor $c_{3}$ (the percentage of the time when a snowmobile is used for recreational purposes) is arbitrarily set at 0.5 for all states. This assumption is likely to be subject to criticism. However, the major purpose of this estimation procedure is to development a quantitative measure to equitably apportion the National Recreational Trails Trust Fund among states. Setting $c_{3}$ to a value other than 0.5 to reflect different degrees of non-recreational snowmobile 


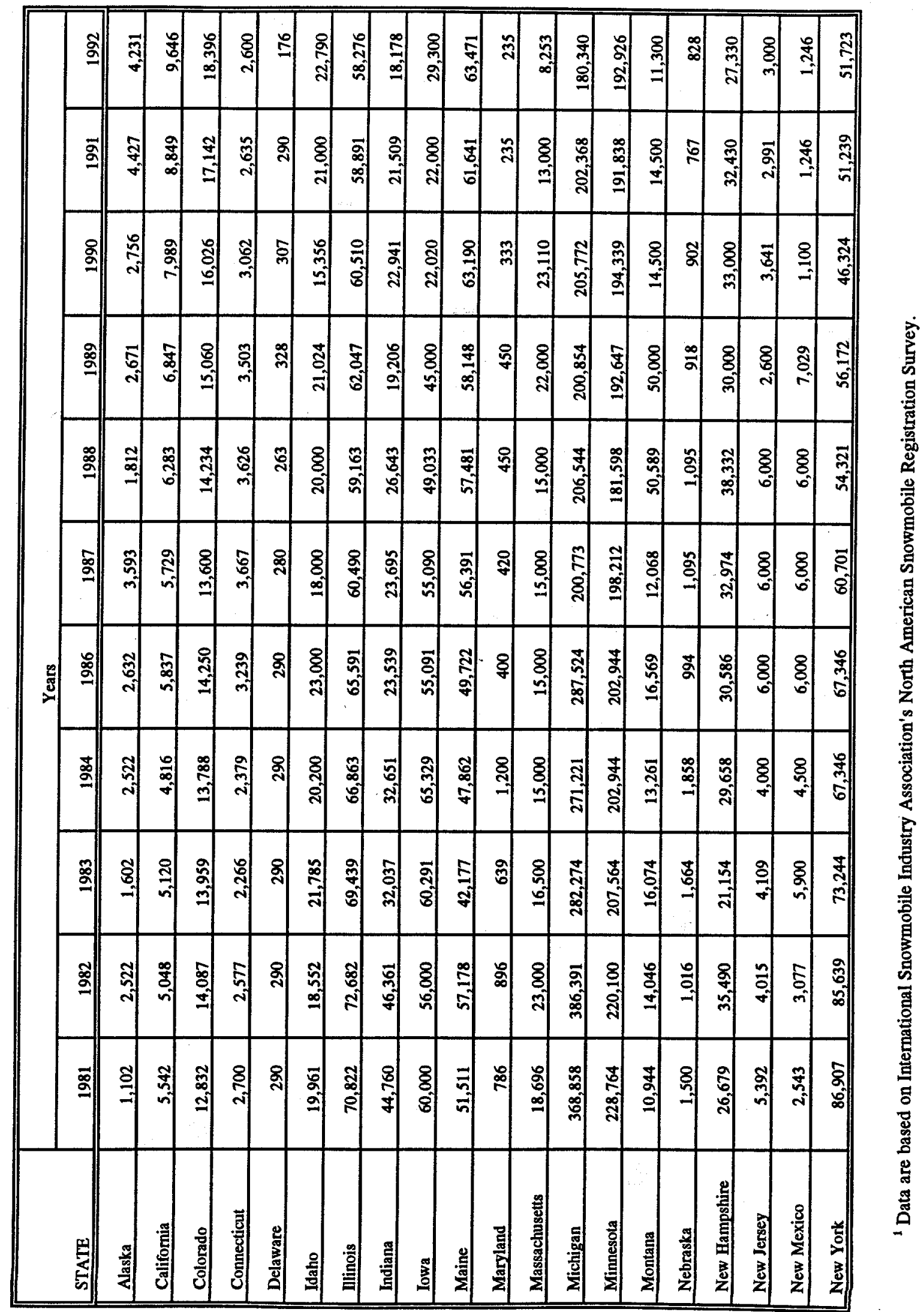




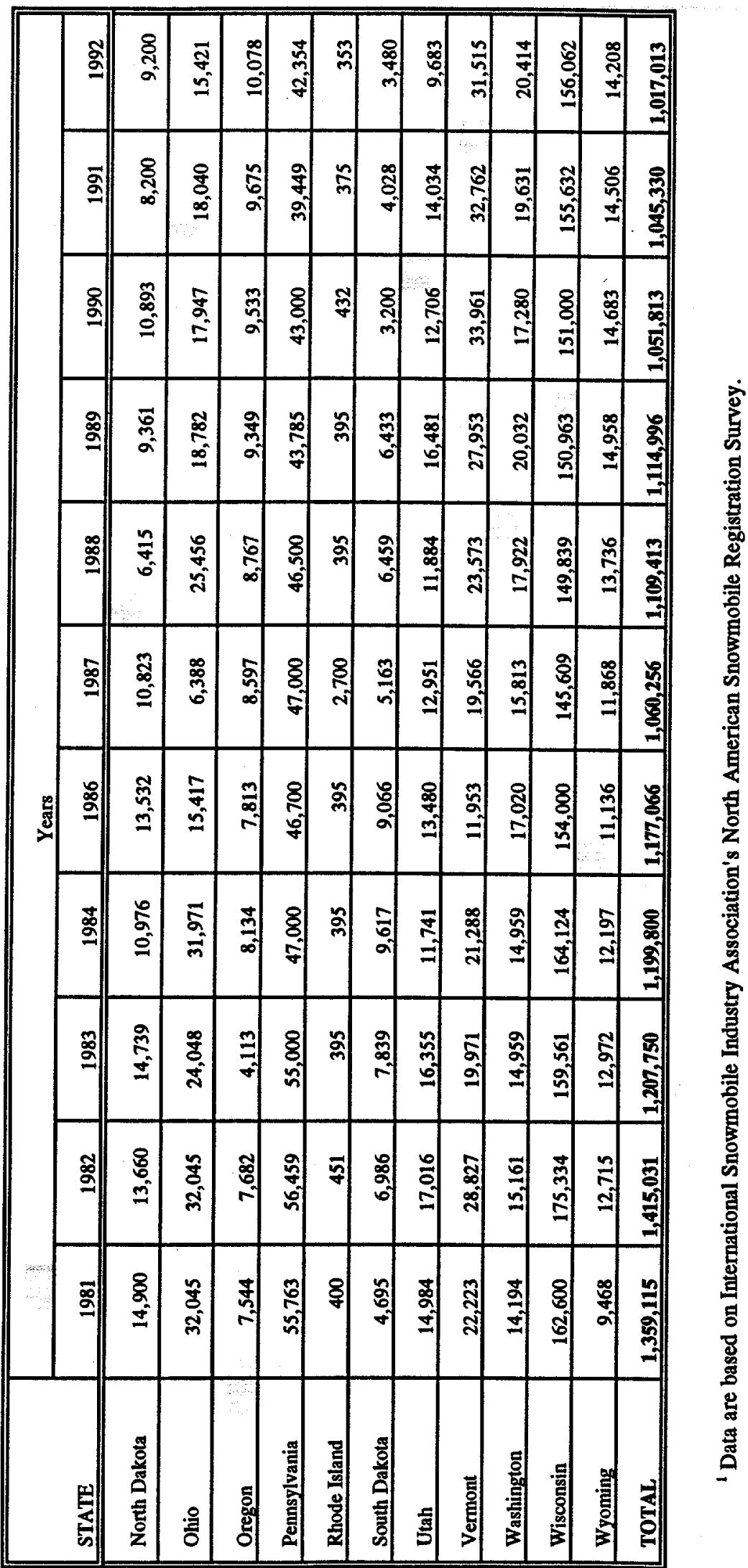


use will not alter the final state distribution unless data on state-specific $c_{3}$ are available (i.e., $c_{3}$ varies from one state to the next).

In the ISIA survey, participating states are asked to estimate the number of unregistered snowmobiles. In the 1991-1992 survey, four states (California, Colorado, Idaho, and New Hampshire) provided the number of unregistered snowmobiles. The state-specific percentage of unregistered snowmobiles $\left(c_{1}\right)$ ranges from $5 \%$ in New Hampshire to $55 \%$ in Idaho. ISIA estimated that the national average is $20 \%$ using these survey data. For states that did not provide any information on unregistered snowmobiles in ISIA's annual survey, the ISIA estimate of $20 \%$ was used to adjust for unregistered snowmobiles. The estimated numbers of snowmobiles used off-highway for recreational purposes by state are based on ISIA's survey results, with one exception (Arizona), and are presented in Table 25. The State of Arizona, based on its two off-highway vehicle surveys, estimated that there were 1,088 snowmobiles ridden off-the-road in 1990 . This estimate of 1,088 was used by Arizona State to calculate Arizona's snowmobile recreational fuel use. Arizona has never in the past 13 years reported any snowmobile registration data in the ISIA's annual snowmobile survey. This instance reflects a shortcoming of relying on data from the ISIA survey to estimate numbers of snowmobiles used off-road for recreational purposes -- snowmobile count data are missing for states that are unable or that fail to respond to the ISIA annual survey. Further attempts were made to obtain snowmobile count data by contacting a few state Departments of Transportation and trade associations (e.g., National Sporting Goods Association). Most of the states contacted are unable to provide snowmobile count data because of either no requirement to register snowmobiles, or the absence of a proper procedure to separate snowmobiles from other types of off-road vehicles which are grouped together. Although 
Table 25. Estimated Number of Snowmobiles Used for Off-Road Recreational Purposes and the Corresponding Fuel Consumption, 1992

(After adjusted for unregistered snowmobiles)

\begin{tabular}{|c|c|c|c|}
\hline State & $\begin{array}{c}\text { Number of } \\
\text { Snowmobiles }\end{array}$ & $\begin{array}{l}\text { Fuel Used } \\
\text { (gal.) }\end{array}$ & $\begin{array}{l}\text { Average Fuel Use per } \\
\text { Snowmobile (gal.) }\end{array}$ \\
\hline 40980134 & প্য & স্যে: & या। \\
\hline Alastiz: & $5.07 \pi$ & 162.470 & 82 \\
\hline 4.18013: & 2.610 & 16.704 & 6.8 \\
\hline Noreansis: & $2: 0.0$ & 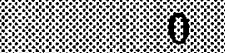 & 80 \\
\hline 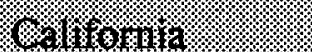 & $(1.865$ & .81 .869 & 12.8. \\
\hline Colorado & 22,443 & 430,908 & 19.2 \\
\hline Connecticut & 3,120 & 59,904 & 19.2 \\
\hline Delaware & 211 & 2,703 & 12.8 \\
\hline D. C. & 0 & 0 & 12.8 \\
\hline Florida & 0 & 0 & 0 \\
\hline (6.8078: & 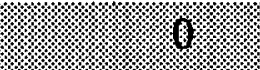 & 3). & 8 \\
\hline 3ravar: & 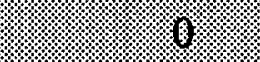 & 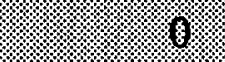 & (8) \\
\hline 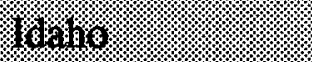 & 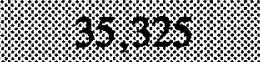 & $904: 307$ & 2.86. \\
\hline 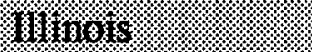 & 693.929. & 899.119 & 12.8 \\
\hline 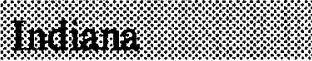 & 218.814 & 270.210 & 10.8 \\
\hline Iowa & 35,160 & 450,048 & 12.8 \\
\hline Kansas & 0 & 0 & 12.8 \\
\hline Kentucky & 0 & 0 & 6.4 \\
\hline Louisiana & 0 & 0 & 0 \\
\hline Maine & 76,165 & $1,949,829$ & 25.6 \\
\hline 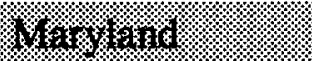 & 282 & 3.610 & 12.8 \\
\hline 14asssactingsers: & $=9.98$ & $=1908.469$ & $(10.2$. \\
\hline 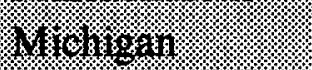 & 240.408 & $4.135 .08 \%$ & 19.2 \\
\hline Nimnesert: & 231.511 & $4: 446.013 .5$ & $18: 2$ \\
\hline Misstsstep? & 20.0 & 2.20 .0 & 2.0 \\
\hline Missouri & 0 & 0 & 6.4 \\
\hline Montana & 13,560 & 347,136 & 25.6 \\
\hline Nebraska & 994 & 19,077 & 19.2 \\
\hline Nevada & 0 & 0 & 19.2 \\
\hline New Hampshire & 28,697 & 734,630 & 25.6 \\
\hline
\end{tabular}




\begin{tabular}{|c|c|c|c|}
\hline State & $\begin{array}{c}\text { Number of } \\
\text { Snowmobiles }\end{array}$ & $\begin{array}{l}\text { Fuel Used } \\
\text { (gal.) }\end{array}$ & $\begin{array}{l}\text { Average Fuel Use per } \\
\text { Snowmobile (gal.) }\end{array}$ \\
\hline $8 \%(1,406)$ & $=9.601 .9$. & $=1.6 .96 \%$ & 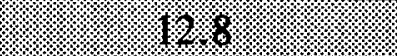 \\
\hline nevilurexico. & $\sqrt{1}, 49 \%$ & $9.1 .9 \%$ & $\sqrt{2} \times 6$ \\
\hline 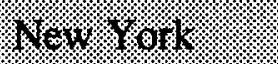 & $6 \% 10.8$ & $1.988 .698 \%$ & 28.6 \\
\hline 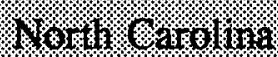 & 6 & \% & 6.6 .4$. \\
\hline 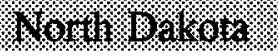 & 1.1 .640 & $14 \% 868$ & 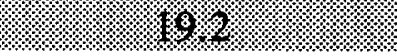 \\
\hline Ohio & 18,505 & 236,867 & 12.8 \\
\hline Oklahoma & 0 & 0 & 6.4 \\
\hline Oregon & 12,094 & 309,596 & 25.6 \\
\hline Pennsylvania & 50,825 & 975,836 & 19.2 \\
\hline Rhode Island & 424 & 5,422 & 12.8 \\
\hline 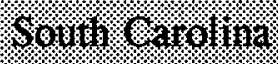 & (1) & 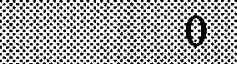 & ;। \\
\hline 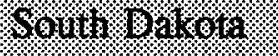 & $14.1 \%$ & $89.1 \%$ & 19.2. \\
\hline Tennessose. & (1. & \%. & o \\
\hline 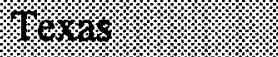 & $=$ & 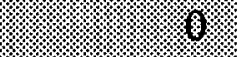 & (1) \\
\hline Hetar: $:=$ & \% & $18 \% 1862$ & 2.8 .6 \\
\hline Vermont & 37,818 & 968,141 & 25.6 \\
\hline Virginia & 0 & 0 & 12.8 \\
\hline Washington & 24,497 & 627,118 & 25.6 \\
\hline West Virginia & 0 & 0 & 12.8 \\
\hline Wisonsin & 187,274 & $3,595,669$ & 19.2 \\
\hline 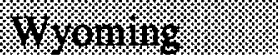 & ঝ & $=1.186 .486$ & 2060 \\
\hline TOTAL & $1,227,563$ & $24,596,602$ & \\
\hline
\end{tabular}

1 Adjusted based on ISIA's usage estimate of 63 gallons per snowmobile. 
snowmobile sales data are reported by a few trade associations, they are not available at the state level.

Based on the survey data, the ISIA estimates that the average annual amount of fuel used per snowmobile is 63 gallons. However, to account for the difference in snowmobile usage among states, data on the average annual amount of snowfall are used to derive a set of adjustment factors, ranging from 0 to 5 (Table 26). The adjustment factor of 0 indicates that the amount of snowfall is negligible (such as in Hawaii or Florida), while an adjustment factor of 5 indicates the heaviest amount of snowfall (such as in Alaska). It is recognized that snowmobile usage is more a function of the amount of snow accumulated on the ground than of the amount of snowfall. Since data on state-specific snow accumulation are not readily available, the average annual amount of snowfall is used as a proxy of snow accumulation. The average annual amount of snowfall is estimated from a map of mean annual snow fall. All states that did not report any snowmobile registration data in the ISIA's survey are assumed to have no snowmobile activities, except Arizona.

The estimated annual fuel used by snowmobiles for off-highway recreational purposes is calculated by

$$
\mathrm{Gal}_{3,1, t}=N_{3,1, t} \times\left(63 \text { Gallons } \times c_{3}\right) \times \zeta_{j}
$$

where $N_{3, j, t}=$ the number of snowmobiles, registered and unregistered, in state $j$ in year $t ; c_{3}$ (the percentage of the time when a snowmobile is used for recreational purposes) $=0.5$, and $\zeta_{j}=$ the adjustment factor for state $j$ in terms of the 
Table 26. Average Annual Amount of Snow Fall and the Correction Factors For Snowmobile Usage

\begin{tabular}{|c|c|c|c|c|c|}
\hline State & $\begin{array}{l}\text { Mean Annual } \\
\text { Snow Fall }{ }^{1} \\
\text { (in) }\end{array}$ & $\begin{array}{c}\text { Correction } \\
\text { Factor } \\
\end{array}$ & State & $\begin{array}{l}\text { Mean Annual } \\
\text { Snow Fall } \\
\text { (in) }\end{array}$ & $\begin{array}{c}\text { Correction } \\
\text { Factor }\end{array}$ \\
\hline Arabaina & 28.8 & (8) & Missoun: & 8.16 & (1) \\
\hline Alast: & 1.93 & s. & nebrask & 32.64 & 8 \\
\hline 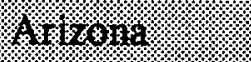 & 8 & (3) & 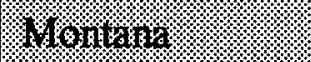 & 6.64 .86 & 8 \\
\hline 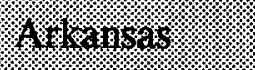 & 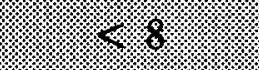 & 8 & 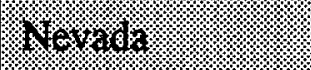 & 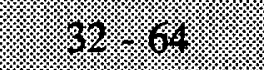 & 3 \\
\hline Canfonia & 16.82 & 2 & 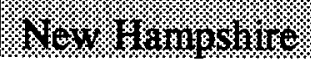 & 64.96 & 4 \\
\hline Colorado & $32-64$ & 3 & New Jersey & $16-32$ & 2 \\
\hline Connecticut & $32-64$ & 3 & New Mexico & $16-32$ & 2 \\
\hline Delaware & $8-16$ & 2 & New York & $64-96$ & 4 \\
\hline D.C & $8-16$ & 2 & North Carolina & $8-16$ & 1 \\
\hline Florida & $<8$ & 0 & North Dakota & $32-64$ & 3 \\
\hline 6.eng.8: & 8.8 & 98 & OMnio & 16.82 & 2. \\
\hline Harara: & 2.83 & 8 & (6) & 8 & (1) \\
\hline $192110=$ & 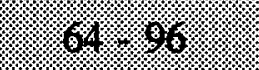 & (4) & 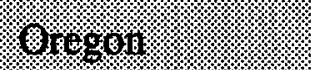 & 684.96 & 4 \\
\hline Minos: & 16.32 & 2. & Peñoyltan: & $32: 04$ & 8 \\
\hline Madrasa & 16.82 & 8 & 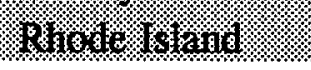 & (10. 182. & (2.: \\
\hline Iowa & $16-32$ & 2 & South Carolina & $<8$ & 0 \\
\hline Kansas & $16-32$ & 2 & South Dakota & $32-64$ & 3 \\
\hline Kentucky & $8-16$ & 1 & Tennessee & $<8$ & 0 \\
\hline Louisiana & $<8$ & 0 & Texas & $<8$ & 0 \\
\hline Maine & $64-96$ & 4 & Utah & $64-96$ & 4 \\
\hline 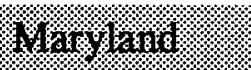 & 16.17 .32 & 2). & Vernontr: & $644:=98$ & ;i: \\
\hline Massactiused & 32.64 & 8 & 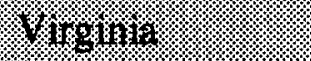 & $16-12$ & 2 \\
\hline Michigar: : & 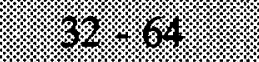 & 3:- & ingsining & 698.96 & 3. \\
\hline vilnesota: & 32.84 & 3. & 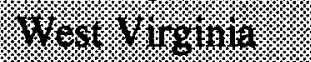 & $16:=32$ & 2 \\
\hline \multirow{2}{*}{ Mississipi: } & $=2.8$ & 0 & Wrisornsm & .82 .64 & 3 \\
\hline & & & Wyoming & $64-96$ & 4 \\
\hline
\end{tabular}

1 Deduced based on the map of mean annual snow fall published in the "The National Atlas of the United States of America," p. 100. U.S. Department of Interior, Washington, D.C. 
difference in the amount of snow fall (Table 26). The resulting estimates are in Table 25.

\subsection{Evaluation of States' Estimates of Snowmobile Usage}

Eight states conducted their own snowmobile surveys to estimate the numbers of snowmobiles and the corresponding fuel use. They were: Arizona, California, Colorado, Minnesota, North Dakota, Oregon, Utah and Washington. Four of the surveys focused on all off-road vehicles, including snowmobiles, and were discussed in Sections 2.2 and 3.2. These surveys are discussed briefly and their results on snowmobiles are summarized. Surveys specifically for snowmobiles were conducted by the states of Minnesota, North Dakota, Oregon and Washington; and are discussed here in more detail.

\section{Arizona}

The State of Arizona conducted two different surveys during 1989-1990 -one for the winter and one for the summer season. Each survey covered a six month period and contacted 1,000 households using a random dialing procedure that selected a number of telephone numbers in proportion to each county's population size. Based on the survey results, Table 27 presents the population estimates. To avoid double counting, Arizona excluded rented or borrowed vehicles from the estimated numbers of snowmobiles used off-road, as reported in Table 27. No explanations were offered in the report as to why snowmobiles in Arizona were used in the summer months but not in winter months. Although Arizona survey collected information on miles driven by snowmobiles, the reported survey results do not include any usage information by vehicle class. 
Table 27. Estimated Number of Snowmobiles Used for Off-Highway in Arizona, 1990

\begin{tabular}{||l|c|c||}
\hline & $\begin{array}{c}\text { Estimated Total } \\
\text { Snowmobile Population }\end{array}$ & $\begin{array}{c}\text { Estimated Number } \\
\text { of Snowmobiles } \\
\text { Used Off-road }\end{array}$ \\
\hline Based on the Winter Survey & 13,315 & 0 \\
\hline Based on the Summer Survey & 9,321 & 2,175 \\
\hline Survey Average & 11,318 & 1,088 \\
\hline Based on ISIA's Annual & 0 & \\
\hline Surveys & & \\
\hline
\end{tabular}

Source: "The 1990 Arizona Off-Highway Vehicle Survey," College of Public Programs, Arizona State University, prepared for the Arizona Departments of Transportation and Game and Fish and Arizona State Parks Board. January 1991.

\section{California}

The State of California randomly selected a sample of 20,394 households to estimate 1989 off-road fuel use. The survey was completed with a response rate of almost $60 \%$. To determine whether the sampled off-highway vehicles were registered, they were matched to California's Department of Motor Vehicles' registration file of off-highway vehicles. Based on the matching results, the ratio of unregistered snowmobiles to registered snowmobiles was seven to one. This ratio was based on an observation of 8 snowmobiles of which only 1 could be matched with DMV records. The total number of snowmobiles in California was estimated as in Table 28. One of the most significant factors contributing to the difference between California's estimates and ISIA's estimates is probably the correction factor for unregistered snowmobiles. 
Table 28. Estimates of California Snowmobile Off-Highway Recreational Fuel Use, 1989

\begin{tabular}{||c|c|c||}
\hline & State's Estimates & ISIA's Estimates \\
\hline Number of Registered Snowmobiles & 6,263 & 6,847 \\
\hline$\times$ & & $2,530^{1}$ \\
\hline $\begin{array}{c}\text { Correction Factor for Unregistered } \\
\text { Snowmobiles }\end{array}$ & 7 & \\
\hline Total Number of Snowmobiles & 50,104 & 9,399 \\
\hline$\times$ & & 63.0 \\
\hline Annual Fuel Used per Snowmobile & 34.9 & \\
\hline$=$ & & 592,137 \\
\hline Total Snowmobile Fuel Use & $1,750,824$ & \\
\hline
\end{tabular}

1 Number of unregistered snowmobiles reported to the ISIA annual survey by the State of California.

\section{Colorado}

A mail survey was done of randomly-selected registered off-road vehicles in Colorado. Since no information is available regarding the important factors, such as the number of households surveyed or the response rate, etc., no assessment is made of the survey results. The State of Colorado estimated that there were a total of 19,620 snowmobiles in Colorado, both registered and unregistered. Each of these snowmobiles, on average, used 81.3 gallons per year, resulting in an estimate of 1,595,190 gallons of fuel used by snowmobiles for offroad recreational purposes (Table 18). 


\section{Minnesota}

Minnesota's Department of Natural Resources has conducted surveys of snowmobilers since 1983/1984. Data from each survey were collected either by phone or through the mail. The methods that were used to select the sample, the exact sample sizes and the response rates were not documented. Historical gasoline consumption for registered snowmobiles used in Minnesota by Minnesotans is presented in Table 29. The number of unregistered snowmobiles in 1990/1991 use season was estimated at $35 \%$ of the number of registered snowmobiles. Furthermore, registered and unregistered snowmobiles were assumed to have identical use levels of 40.8 gallons per year, resulting in a total of $10,566,381$ gallons of fuel used by snowmobiles for off-highway recreational purposes.

Table 29. Gas Consumption of Registered Snowmobiles Used in Minnesota by Minnesotans ${ }^{1},{ }^{2}$

\begin{tabular}{||cccccc||}
\hline Year & $\begin{array}{c}\text { Fuel Use/ } \\
\text { Snowmobile }\end{array}$ & $\times$ & $\begin{array}{c}\text { No. Registered } \\
\text { Snowmobiles }\end{array}$ & Total Fuel Use \\
\hline $84-85$ & 20.5 & $\times$ & 203,000 & $=$ & $4,161,500$ \\
$85-86$ & 31.9 & $\times$ & 181,000 & $=$ & $5,773,900$ \\
$86-87$ & 18.6 & $\times$ & 170,000 & $=$ & $3,162,000$ \\
$88-89$ & 51.0 & $\times$ & 184,000 & $=$ & $9,384,000$ \\
$89-90$ & 36.4 & $\times$ & 184,000 & $=$ & $6,697,600$ \\
$90-91$ & 39.8 & $\times$ & 191,715 & $=$ & $7,630,257$ \\
\hline
\end{tabular}

1 Based on Table 1 of "Gasoline Consumption by Snowmobiles Within Minnesota" by J.C. Vlaming, D. H. Anderson, and G. Flekke, University of Minnesota. February, 1992.

2 No survey was conducted for the $1987 / 1988$ use season. 


\section{North Dakota}

A mail survey of randomly-selected 1,127 registered snowmobile owners was conducted in North Dakota. Of these, 647 completed questionnaires, yielding a response rate of $58 \%$. Survey participants were contacted three times. First, the questionnaire was mailed to all 1,127 sampled snowmobile owners. Approximately 7 days after the questionnaire was mailed, a thank-you/reminder postcard was sent. Finally, 2 to 3 weeks later, another copy of the questionnaire was sent to all non-respondents.

Twenty-four percent of the respondents did not purchase any fuel to operate their snowmobiles in 1991 , while $3.1 \%$ purchased more than 300 gallons. The reported fuel purchase did not include gasoline used for tow vehicles. The average snowmobile fuel use per household was estimated at 65.8 gallons in 1991, and there were 1.9 snowmobiles per household. The total amount of fuel used by snowmobiles in North Dakota for off-road recreational purposes is estimated as:

$$
\begin{aligned}
& \text { Number of registered snowmobiles } \times \text { annual fuel used per vehicle } \\
& =8,820 \times(65.8 \div 1.9)=305,172 \text { gallons. }
\end{aligned}
$$

North Dakota's estimates of total snowmobile fuel use are substantially lower than estimates based on ISIA's survey results or ORNL's estimates.

\section{Oregon}

Oregon's Department of Transportation commissioned a snowmobile survey in the spring of 1990 to estimate snowmobile gasoline consumption. From the Motor Vehicle Division's snowmobile registration file of 18,037 licenses, a sample 
of 677 snowmobile license numbers were randomly selected. Of these, 513 completed questionnaires were obtained, resulting in a response rate of $76 \%$.

Ninety-five percent of the sampled snowmobiles were primarily used for recreational purposes. For each respondent, the annual fuel consumption was derived as the product of the number of days in a year that the snowmobile was used for recreational purposes and the amount of fuel used on a typical day of recreational use. The average annual fuel used for recreational purposes per sampled snowmobile was 113.9 gallons with a standard error of $3.3^{2}$. The total amount of fuel used by snowmobiles licensed in Oregon was estimated by the state to be $18,037 \times 113.9=2,054,414$ gallons, with a $95 \%$ confidence interval of $1,933,680$ to $2,175,148$. The average difference between the estimated annual fuel use reported directly by the survey respondents and the derived annual fuel use is -3.6 gallons ( \pm a standard error of 9), indicating that the difference is not significantly different from zero. In this calculation, the State failed to eliminate $5 \%$ of the State's snowmobiles that were not used primarily for recreational purposes. The major factor contributing to the difference between Oregon's estimates and ORNL's estimates is the discrepancy in the number of snowmobiles registered in Oregon. Oregon's response to the 1990 ISIA's annual snowmobile survey indicated that there were 9,675 snowmobiles registered in Oregon while the snowmobile fuel consumption estimates are based on a snowmobile registration of 18,037 - a difference difficult to explain.

2 Bodenroeder, P., Berg, H., and McCracken, M. "Annual Gasoline Consumption of Snowmobiles Licensed in Oregon 1989-1990," Oregon State University. Prepared for the Oregon Department of Transportation, July 1990. 


\section{Washington}

Since 1971, the Washington State Department of Licensing and the Parks and Recreation Commission have conducted numerous snowmobile studies to determine snowmobile use, snowmobile facility needs, and the amount of fuel tax to be refunded to the snowmobile program. The 1987-1988 study surveyed all 18,200 snowmobile users registered in the $1987-1988$ season. A total of 4,651 usable survey forms were received, resulting in a response rate of $25.5 \%$. The average number of days that one went snowmobiling was 15.4 days in a winter ${ }^{3}$. The survey estimated that each snowmobile consumed 72.4 gallons in 1988. This estimate is slightly higher than that of ISIA's estimate but is in close proximity. Table 30 provides a comparison of states' snowmobile fuel use estimates.

Table 30. Comparison of States' Snowmobile Fuel Use Estimates (Based on four State surveys and the ISIA survey)

\begin{tabular}{|lc|}
\hline Source & $\begin{array}{c}\text { Average Fuel Use per } \\
\text { Snowmobile }\end{array}$ \\
ISIA & 63 \\
California & 35 \\
North Dakota & 35 \\
Oregon & 114 \\
Minnesota & 41 \\
Washington & 72 \\
\hline
\end{tabular}

3 "1988 Snowmobile Study," Washington State Parks and Recreation Commission, Olympia, Washington. 


\section{CONCLUDING REMARKS}

The 1991 ISTEA established a National Recreational Trails Funding Program and the National Recreational Trails Trust Fund to redirect tax revenues generated from the sales of motor fuel used for off-highway recreational purposes to recreational trail and facility improvements. The major challenge in accomplishing this goal is to determine how the amounts transfered to the Trails Trust Fund can be apportioned equitably to individual states. Technically, each state should receive an amount that equals the tax revenues generated by the sales of motor vehicle fuel sold in that state for off-highway recreational purposes. Unfortunately, this type of information is unavailable. As a result, the FHWA was charged with the development of estimates of the fuel used in each state for offhighway recreational purposes. These estimates will then be used to apportion the Trails Trust Fund to individual states. This technical memorandum documents the estimation procedures.

Two options are available to develop the state distribution to "share" the total tax revenue generated from the sales of motor vehicle fuel used for offhighway recreation. The first one is to rely on the individual states to submit their annual estimates of off-highway recreational fuel use. The advantage of this option is that individual states could devote more resources to this activity, and can receive more cooperation in obtaining the data, than FHWA could. As a result, individual states might be able to produce more reliable estimates than FHWA could. However, this option has three potential drawbacks. First, individual states have a great incentive to over-estimate their off-highway recreational fuel use. Second, the compatibility among methods that the states use to estimate offhighway recreational fuel use becomes an enormous issue in trying to apportion the Trust Fund equitably. Third, not every state submits the required estimate. In the 
1992-1993 period, only twenty-three states did, and some of the estimates are for 1987 while others are for 1989 or 1990 (Table 7). Consequently, an estimation procedure would need to be developed for the remaining 22 states that failed to submit data, adding further complexity to the compatibility issue.

To overcome the disadvantages of the first option, a second option is to "standardize" the estimation procedure and develop a common tool which can objectively apportion the National Recreational Trails Trust Funds on an annual basis. Two features of this option are that: (1) individual state shares of the total Trust Funds are developed using a uniform approach, and (2) data needed for the estimation purpose are publicly available and easily obtainable so that estimates for all subsequent years can be easily generated. It is these two factors that govern the development of ORNL's estimation procedure discussed in this report. It is also due to these two factors that ORNL's estimates are used instead of individual states' estimates.

Vehicles included in this study are: light trucks, motorcycles, ATVs, and snowmobiles. "Light trucks" include pickups, vans, minivans, and utility vehicles with a maximum gross vehicle weight less than or equal to 10,000 pounds. The estimated total number of light trucks used for off-highway recreation is defined as the total number of "full light truck equivalents." That is, if $30 \%$ of the total annual miles driven by a light truck is for off-highway recreation, then this light truck is counted as 0.30 of a full vehicle equivalent.

The major data source in estimating the light trucks' total fuel used for offhighway recreation is the Truck Inventory and Use Survey (TIUS). Although TIUS did not explicitly collect data on the percentage of the annual mileage that a vehicle was used off-the-road for recreational purposes, it did ask the respondents 
to report the average percentage of the annual miles that the vehicle was operated off-the-road, and the percentage of the miles used for personal use. The product of these two percentages is taken to be a proxy for the probability that a truck will be used off-the-road for recreation. The state-specific probabilities are generated from the TIUS data and are used, in conjunction with the truck registration data ${ }^{4}$, to estimated the number of "full light truck equivalents" used in each state for offhighway recreation. The percent of annual miles traveled off-the-road for recreation is estimated by the weighted average product of the percentage of the miles that a truck was used off-the-road and the percentage of the miles that it was used for personal purposes, taking into account the annual miles driven by this truck. The state-specific total number of miles traveled off-the-road for recreation is then converted to the amount of fuel consumed by using the average on-road fuel economy of 2-axle 4-tire trucks ${ }^{5}$ discounted by 0.9 for the difference between the on-road and the off-road fuel economies.

In the cases of motorcycles, ATVs and snowmobiles, data are considerably sparser than that of light trucks. Estimates of motorcycle and ATV fuel used for off-highway recreation are largely based on vehicle population estimates compiled annually by the Motorcycle Industry Council (MIC) and vehicle usage data collected in two state surveys (California and Oregon.) Although the MIC has conducted periodic surveys of motorcycle and ATV annual usage, the information is, unfortunately, considered proprietary and only limited access is allowed.

Due to lack of more detailed data, it is assumed that whenever motorcycles are used off-the-road, they are done so for recreational purposes. A recent MIC

4 Compiled by the R. L. Polk and Company.

5 Reported in the Table VM-1 of the Highway Statistics. 
survey on ATVs provides an estimate of the percentage of ATV off-road riding for utility purposes, which allows better estimates of the number of ATVs used off-theroad for recreation.

Unlike light trucks, there is no survey of motorcycles and ATVs that provides consistent estimates of annual fuel use by state. In addition to the MIC's periodic surveys, there are six state surveys conducted to estimate the number of motorcycles and ATVs used off-road, and the corresponding fuel consumption. The six states are: Arizona, California, Colorado, Oregon, Utah and Washington. Several options are considered to estimate annual fuel use. Since every survey has its strengths and limitations, we synthesize all available estimates. After a detailed evaluation of MIC survey and individual state surveys, a set of weighting factors is subjectively determined. A higher subjective weight is given to a usage estimate from an approach that is more reliable for the purpose of our study. Based on the weighted averages of annual fuel use, three sets of fuel usage estimates are calculated for motorcycles and ATVs, respectively. One set is based on the low fuel use estimate, one on the high fuel use estimate and the third one on the average of the low and high estimates.

The International Snowmobile Industry Association (ISIA) has been conducting its annual registration survey since 1981. Thirty-one states participated in the survey. In this estimation procedure, all snowmobiles are assumed to be used exclusively off-the-road and the percentage of time that a snowmobile is used for recreational purposes is arbitrarily set at 0.5 for all states. Until state-specific information on the percentage of time that a snowmobile is used for nonrecreational purposes becomes available, setting this value to 0.5 is inconsequential since the objective of this estimation procedure is to develop state shares so that the Trails Trust Fund can be equitably apportioned among states. 
Based on the ISIA's survey data, the estimated annual fuel use per snowmobile is 63 gallons. To account for the difference in snowmobile usage among states, data on the average annual amount of snowfall are used to derived a set of adjustment factors -- 0 being a negligible amount of snowfall and 5 being the heaviest amount of snowfall. However, it is recognized that snowmobile usage is more a function of the amount of snow accumulated on the ground than of the amount of snowfall. Under the circumstance where data on snow accumulation are lacking, the amount of average annual snow fall is used as a proxy.

Table 31 presents the estimated state shares of total fuel used for offhighway recreational purposes. Estimates of motorcycle and ATV fuel used offroad for recreation are based on the average of the low and high fuel use estimates. 


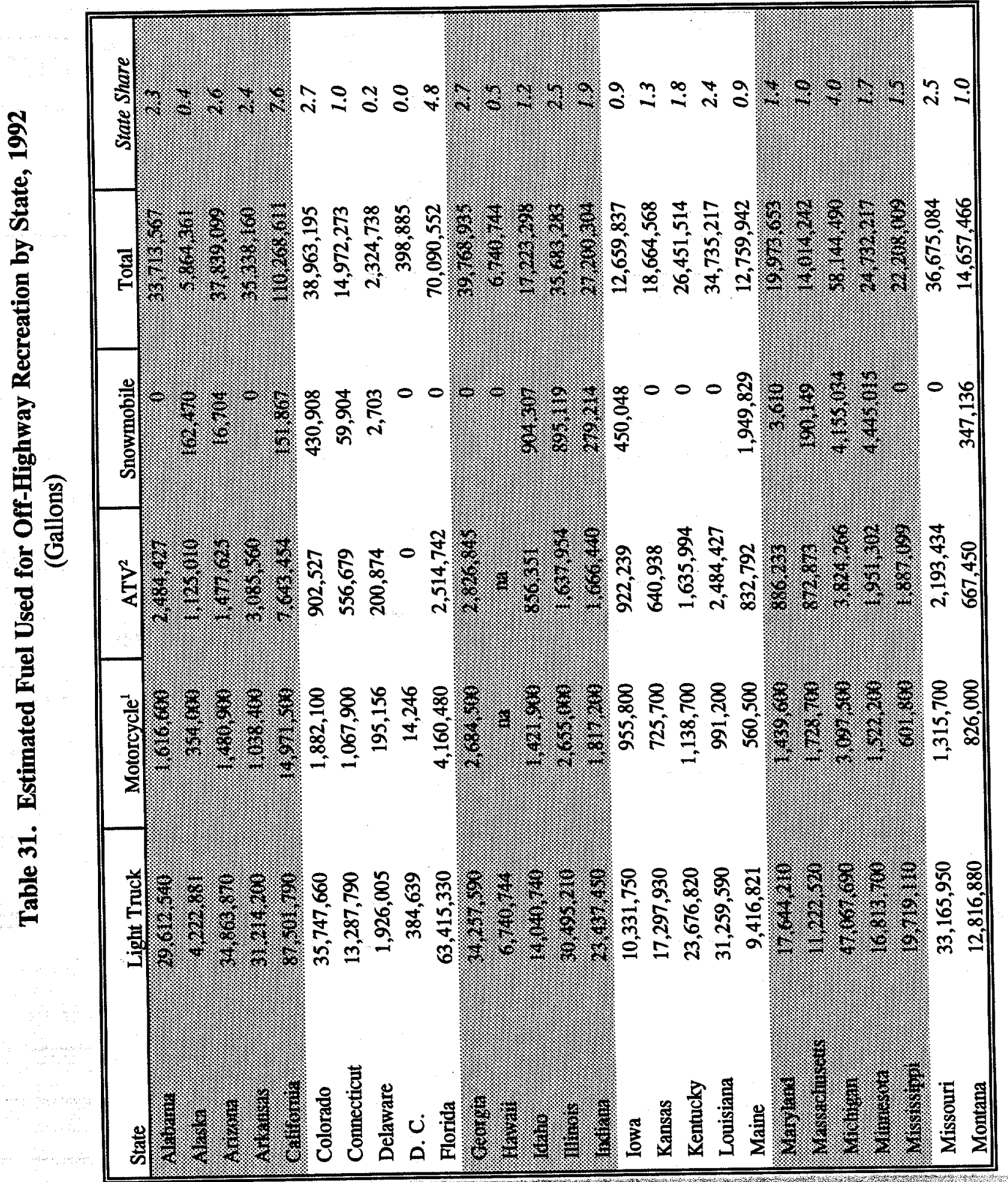




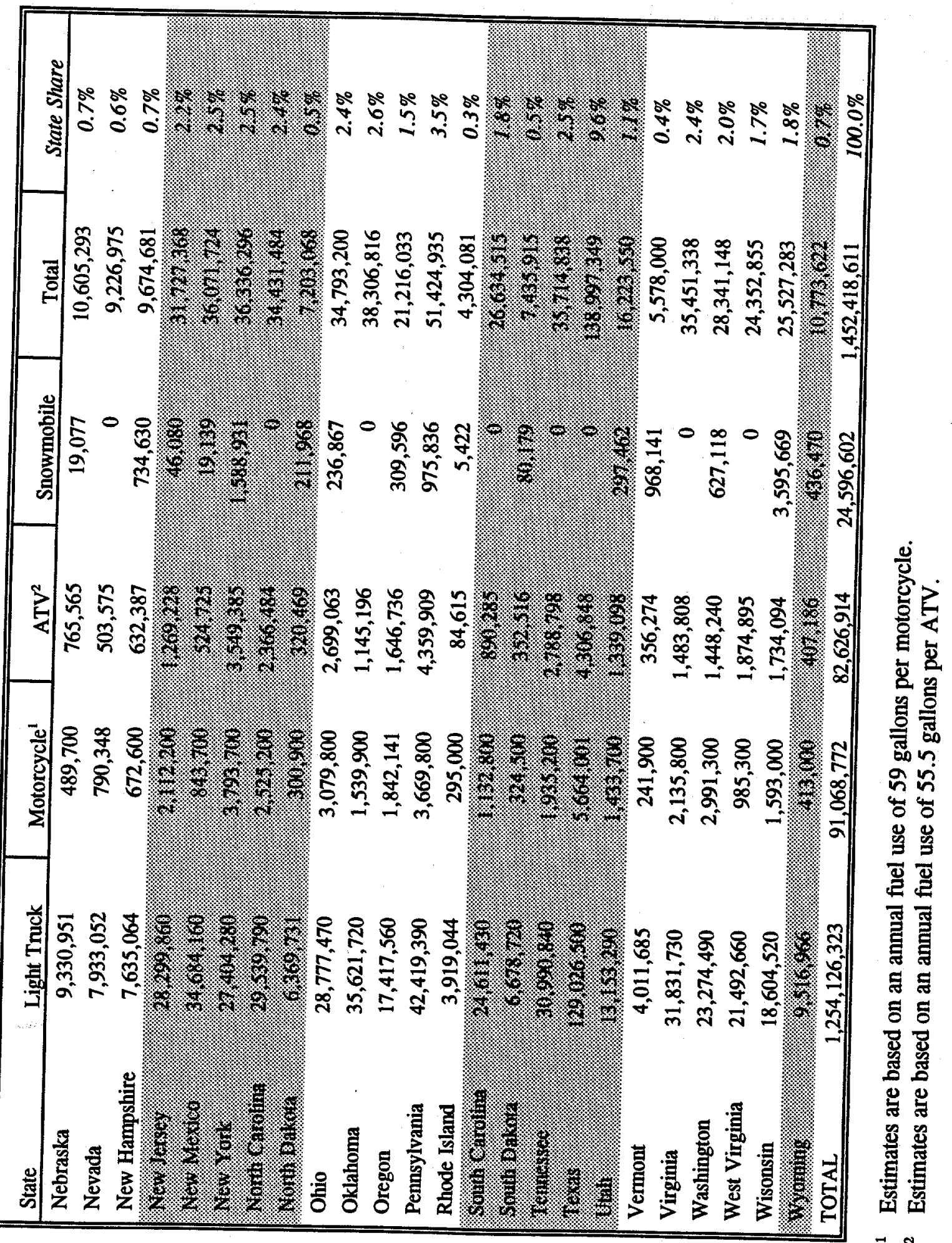




\section{APPENDIX A}

\section{COMPUTER PROGRAM ESTIMATING \\ OFF-HIGHWAY RECREATIONAL FUEL USE}

The main objective of this program is to estimate the number of vehicles used for off-the-road recreational purposes and the corresponding fuel use. Three categories of vehicles are included in this program: light trucks, motorcycles and all terrain vehicles (ATVs), and snowmobiles. This program allows the user to update/edit the data input files, execute separate estimation models -- one for each type of vehicle, and display the output files. A simple menu-driven interface is provided in this program to accomplish these tasks. Currently, this program is named GO. All of the input and output files listed below are manipulated by this program.

For each class of vehicles, the future vehicle population is forecasted by using an exponential smoothing based on past vehicle population data. This forecasting feature may be turned off by selecting the default menu setting under which vehicle population is assumed to remain constant. Estimates of fuel consumption are then computed for the projected vehicle population based on annual fuel usage estimates and other correction factors. The two basic tasks that require input from the model user are annually updating the data, and executing the model. These two tasks are explained in the following section for each of the three different vehicle classes. This program also allows the model user to alter model parameters and assumptions, such as fuel use level, and correction factor for unregistered vehicles. 


\section{LIGHT TRUCKS}

\section{$1.1 \quad$ Updating Data Sources}

The file PICKUP1.DAT contains light truck statistics on off-the-road usage, by state, based on the 1987 Truck Inventory Use Survey (TIUS). This file should updated when the new TIUS data become available. The file PICKUP2.DAT contains national totals of the number of trucks, the average fuel economy and the average fuel consumption of 2-axle 4-tire trucks, and the annual miles driven by 2-axle 4-tire trucks. This file needs to be updated annually.

\subsection{Executing the Model}

The model user may investigate the effect of an exponential smoothing forecast relative to a "no change" forecast. The model setting menu provides a "Yes/No" switch for employing an exponential smoothing forecast. A "Yes" setting uses the exponential smoothing forecast while a "No" setting yields a "no change" forecast.

\section{MOTORCYCLES \& ATVS}

\subsection{Updating Data Sources}

Two files, MCATV.DAT and ATV.DAT, contain population estimates of motorcycles and ATVs. The file MCATV.DAT has time series data of motorcycles and ATVs combined, by state, from 1984 to 1991 . The file $A T V . D A T$ contains population estimates of only ATVs, by state, for the year 1991. That was the year when motorcycle and ATV estimates were reported separately for the first time by 
the Motorcycle Industry Council (MIC). The time series data of the combined vehicle population of motorcycles and ATVS are used to forecast the future combined population. However, it is important to estimate the ATV population separately for two reasons. First, fuel use by motorcycles is different from fuel use by ATVs. Second, the percentage of the time that motorcycles are used for recreational purposes is different from that of ATVs. These two files, $M C A T V . D A T$ and $A T V . D A T$, should be updated annually.

\subsection{Executing the Model}

The estimation model in this program allows the user to consider more than one set of vehicle usage estimates at the state level. For example, the sensitivity of a state's shares of gasoline consumption with respect to high/low usage estimates may be easily evaluated with this model. Currently, two different sets of total fuel use estimates are included based on reasonably conservative high/low estimates of individual vehicle's fuel use. Estimates based on the low fuel use estimates are denoted as Method 1, and estimates based on the high estimate as Method 2. The model-setting menu allows the user to indicate which method to use. The program will allow additional sets of fuel usage estimates to be input and evaluated. As mentioned in Section 1.2, control of the exponential smoothing option is provided under the model setting menu.

\section{SNOWMOBILE}

\subsection{Updating Data Sources}

The file SNOWI.DAT contains estimates of snowmobile population, by state, based on snowmobile registration data provided by the International 
Snowmobile Industry Association (ISIA). This file should be updated annually. The file SNOW2.DAT contains the estimated percentage of unregistered vehicles at the state level, annual fuel consumption per vehicle, and correction factors for the amount of snow fall (scale of 0-9). The percentage of unregistered vehicles is based on the ISIA's annual survey of snowmobile registration. The regional correction factor for the amount of snow fall is a rough attempt at adjusting for state variations in snow availability.

\subsection{Executing the Model}

As with motorcycles and ATVs, control of the exponential smoothing option is provided under the model setting menu. Assumptions regarding the key factors, such as the percentage of unregistered snowmobiles, annual fuel usage, and snow fall are contained in the data file SNOW2.DAT. The UPDATE SNOWMOBILE DATA/ EDIT SNOWMOBILE USAGE DATA menu may be used to alter these estimates. 
Disk Contents

\section{MAIN PROGRAM}

GO

EXE

36750

AUXILIARY PROGRAMS CALLED BY GO

$\begin{array}{lll}\text { ALLN } & \text { EXE } & 110424 \\ \text { MCYCLE } & \text { EXE } & 58748 \\ \text { PICKUPO } & \text { EXE } & 42468 \\ \text { SNOW0 } & \text { EXE } & 39407 \\ \text { LIST } & \text { COM } & 8191\end{array}$

DATA INPUT FILES

ATV DAT 1378 - ATV Population by state

ATVCRT DAT 1406 - ATV Non recreational usage correction factor

GAS DAT 3049 - Motorcycle \& ATV annual gasoline usage estimates

MCATV DAT 5536 - Motorcycle \& ATV combined population by state

METHODS DAT 258 - Model default settings

PICKUP1 DAT 3088 - 1987 TIUS off road usage estimates

PICKUP2 DAT 1286 - National annual estimates of Truck population \& fuel usage

SNOW1 DAT 5673 - Snowmobile population by state

SNOW2 DAT 2710 - Snowmobile gasoline usage estimates 
A - 6

Fuel Used for Off-Highway Recreation

MOTOR OUT 4228 - Motorcycle population \& gasoline usage estimates

PICKUP OUT 2613 - Off road truck population \& gasoline usage estimates

SNOW OUT 2575 - Snowmobile population \& gasoline usage estimates

TOTALGAL OUT 4921 - Total gallons summary

TOTALNUM OUT 4187 - Total number of vehicles summary

SOURCE CODE FILES

GO BLD

MCYCLE BLD

PICKUPO BLD

SNOWO BLD

ALLN FOR 


\section{INTERNAL DISTRIBUTION}

1. M. S. Bronzini

2. J. B. Cannon

3. S. C. Davis

4. P. S. Hu

5. M. A. Kuliasha

6. A. Lu

7. R. B. Shelton
8. D. A. Trumble

9. ORNL Patent Office

10-11. Central Research Library

12. Document Reference Section

13-14. Laboratory Records

15. Laboratory Records--RC

\section{EXTERNAL DISTRIBUTION}

16. D. R. Bohi, Director, Energy and Natural Resources Division, Resources for the Future, 1616 P Street NW, Washington, DC 20036

17. T. E. Drabek, Department of Sociology, University of Denver, Denver, Colorado 80208-0209

18. C. D. MacCracken, President, Calmac Manufacturing Corporation, P.O. Box 710, Englewood, New Jersey 07361

19. J. B. Shrago, Director, Office of Technology Transfer, 405 Kirkland Hall, Vanderbilt University, Nashville, Tennessee 37240

20. G. F. Sowers, Senior Vice President, Law Companies Group, Inc., 114 Townpark Drive, Suite 250, Kennesaw, Georgia 30144-5599

21. C. M. Walton, Paul D. and Betty Robertson Meek Centennial Professor and Chairman, Department of Civil Engineering, College of Engineering, The University of Texas at Austin, Cock Hall, Suite 4.2, Austin, Texas 78712

22-41. C. S. Edwards, Federal Highway Administration, Department of Transportation, HPM10, 400 Seventh Street SW, Room 3306, Washington, DC 20590

42-47. Center for Transportation Analysis, Energy Division, 5500A, Room A216

48-49. OSTI, U. S. Department of Energy, P.O. Box 62, Oak Ridge, Tennessee 37831

50. Office of Assistant Manager of Energy Research and Development, DOE/ORO, P.O. Box 2001, Oak Ridge, Tennessee 37831-8600 


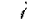

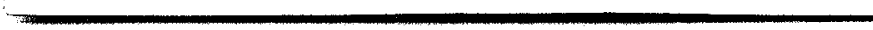

